\title{
Efferent connections of the parvalbumin-positive (PV1) nucleus in the lateral hypothalamus of rodents
}

\author{
Marco R. Celio ${ }^{1,2}$, Alexander Babalian ${ }^{1}$, Quan Hue Ha${ }^{2}$, Simone Eichenberger ${ }^{1}$, Laurence \\ Clément $^{1}$, Christiane Marti ${ }^{1}$, and Clifford B. Saper ${ }^{2}$ \\ ${ }^{1}$ Anatomy Unit, Department of Medicine and "Program in Neuroscience", University of Fribourg, \\ $\mathrm{CH}-1700$ Fribourg \\ 2Department of Neurology and "Program in Neuroscience", Harvard Medical School, Beth Israel \\ Deaconess Medical Center, 330 Brookline Avenue, Boston, MA 02215, USA
}

\begin{abstract}
A solitary cluster of parvalbumin-positive neurons - the PV1-nucleus - has been observed in the lateral hypothalamus of rodents. In the present study, we mapped the efferent connections of the rodent PV1-nucleus using non-specific antero- and retrograde tracers in rats, and chemoselective, Cre-dependent viral constructs in parvalbumin-Cre mice.

In both species, the PV1-nucleus was found to project mainly to the periaqueductal grey matter (PAG), preponderantly ipsilateral. Indirectly in rats and directly in mice, a discrete, longitudinallyorientated cylindrical column of terminal fields (PV1-CTF) was identified ventrolateral to the aqueduct on the edge of the PAG. The PV1-CTF, which is particularly dense in the rostral portion, located in the supraoculomotor nucleus (Su3), is spatially interrupted over a short stretch at the level of the trochlear nucleus and abuts caudally on a second parvalbum in-positive (PV2) nucleus. The rostral and the caudal portions of the PV1-CTF consist of axonal endings that stem from scattered neurons throughout the PV1-nucleus. Minor terminal fields were identified in a crescentic column of the lateral PAG, as well as in the Edinger-Westphal-, the lateral habenularand the laterodorsal tegmental nuclei.
\end{abstract}

So far no obvious functions can be attributed to this small, circumscribed column ventrolateral to the aqueduct, the prime target of the PV1-nucleus.

\section{Keywords}

axonal tracing; Cre-dependent viral constructs; periaqueductal gray; ventrolateral column; Su3; PV2; blood pressure; vocalization; REM-sleep; adeno-associated virus

\footnotetext{
(C) 2013 Wiley Periodicals, Inc.

Corresponding author: Marco R. Celio, Anatomy Unit and "Program in Neuroscience", Department of Medicine, University of Fribourg, Rte. A. Gockel 1, CH-1700 Fribourg, Switzerland. Tel.: +41 2630084 91; Fax: +41 2630097 33; marco.celio@ unifr.ch. MRC spent sabbatical leaves at HMS in 1997 and 2008.

This paper is dedicated to Antonia Milroy, superb technician, dedicated teacher and enthusiastic neuroscientist, on the occasion of her $74^{\text {th }}$ birthday.

Statement of conflict of interest: none.

Statement of author contributions: MRC and CBS oversaw the project, evaluated and documented the results and wrote the paper. $\mathrm{AB}$ made the stereotactic injections in mice and SE and QHH those in rats. LC and CM prepared the sections and performed immunohistochemistry.

Part of the results described in this paper were presented at the European Neuroscience Meeting in Barcelona, 2012 (Babalian A, Clement L, Marti C, and Celio MR (2012) Projections of the parvalbumin nucleus of the lateral hypothalamus (PV1-nucleus) in the mouse. 8th FENS Abstracts vol. 6, 112.01).
} 


\section{INTRODUCTION}

The lateral hypothalamic area (LHA) is a complex region consisting of many different cell types mingling with the longitudinally directed fibers of the medial forebrain bundle ( $\mathrm{mfb}$ ). In early studies, the projections of the LHA could not be distinguished from those of axons traveling in the medial forebrain bundle by using degenerative techniques (Chi and Flynn, 1971; Guillery, 1957). However, with the advent in the 1970s of more sophisticated, axonal transport-tracing techniques, the anterior, tuberal and posterior regions of the LHA were found to have different patterns of projection (Berk and Finkelstein, 1982; Saper et al., 1976; Saper et al., 1979). More recently, the projections of much smaller regions of the LHA, such as the juxtadorsomedial, juxtaparaventricular and suprafornical regions, have been examined using Phaseolus leucoagglutinin (PHAl) as an anterograde tracer and cholera toxin B (CTB) as a retrograde one (Hahn and Swanson, 2010; Hahn and Swanson, 2012). However, these pathways include axons stemming from many chemically and physiologically distinct neuronal populations, which makes it difficult to elucidate their potential functional significance.

The identification of neuropeptides that are specific to the LHA has permitted a much more precise delineation of the connections of the nerve cells that synthesize them. For example, the projections of the orexin- (or hypocretin-) secreting neurons and of the neighboring melanin-concentrating hormone secreting neurons can be readily traced, as these peptides are synthesized by cells occurring exclusively in the LHA. Consequently, their projections can be revealed immunohistochemically (Bittencourt et al., 1992; Chemelli et al., 1999; Peyron et al., 1998). Although these studies have furnished useful information regarding the possible functions of the implicated cell groups, the methodology is of course applicable only to those neuronal populations of the LHA that contain unique peptides.

A more common situation is exemplified by the parvalbumin-positive (PV1) nucleus (Celio, 1990; Girard et al., 2011; Meszar et al., 2012), which is lodged in the LHA, adjacent to the optic tract. Although the group of parvalbum in-positive neurons in this location is quite distinct, many other PV-immunoreactive neurons are scattered throughout the brain. Consequently, the projections of the PV1-nucleus cannot be inferred simply by following the ramifications of PV-immunoreactive axons. To characterize the projections of the PV1nucleus in the present study, non-selective anterograde and retrograde tracing methods were utilized in rats, and chemo-selective tracing-techniques in PV-Cre mice (Hippenmeyer et al., 2005). In the latter approach, adeno-associated viral vectors expressing red or green fluorescent proteins in a Cre-dependent manner (Yonehara et al., 2011) were injected into the PV1-nucleus pf parvalbumin-Cre mice. These experiments in rodents permitted us to identify a narrow column located at the edge of the PAG, ventrolateral to the aqueduct, as the prime projection target of the PV1-nucleus.

\section{MATERIALS AND METHODS}

The overall study was approved by the Veterinary Commission for Animal Research of the Canton of Fribourg, Switzerland. All animals prepared for this study were housed in state of the art animal facilities according to the strict Swiss animal experimentation law. Other animals, drawn from previously published studies (Herbert et al., 1990; Hurley et al., 1991; Moga et al., 1990), had been housed at the University of Chicago Pritzker School of Medicine animal facility, and protocols had been approved by that institution's animal care and use committee. 


\section{Rat tracing experiments}

Wistar rats of both sexes, weighing 275-300 g, were used for the current study. A substantial body of the presented data is drawn from the retrospective analysis of archival specimens that had been prepared for previously published studies (Herbert et al., 1990; Hurley et al., 1991; Moga et al., 1990). The methods used in those experiments were described in detail in those publications, and involved anterograde and retrograde tracing with wheat germ agglutinin-horseradish peroxidase, revealed by a tetramethylbenzidine method, and anterograde tracing with Phaseolus vulgaris leucoagglutinin, demonstrated immunohistochemically.

Antero- and retrograde tracing-The animals prepared for the current study were deeply anesthetized with a mixture of Ketalar [(Parke-Davis) $75 \mathrm{mg} / \mathrm{kg}$ of body weight] and Xylazine [(Streuli) $10 \mathrm{mg} / \mathrm{kg}$ of body weight] prior to tracing application and perfusion. Using a Kopf stereotactic apparatus the brains of six rats were bilaterally injected in the region of the PV1-nucleus of the lateral hypothalamus with $2 \mathrm{nl}$ of biotinylated dextranamine at the following coordinates: anteroposterior Bregma $-2.56 \mathrm{~mm}$; dorsoventral $=-8,6$ $\mathrm{mm}$; lateral : $+2.4 \mathrm{~mm}$ and $-2.4 \mathrm{~mm}$. After two weeks, rats were perfused with $0.9 \% \mathrm{NaCl}$, followed by $4 \%$ paraformaldehyde (in $0.1 \mathrm{M}$ Phosphate buffer, $\mathrm{pH}$ 7.3; PFA). The brains were excised and cryoprotected overnight with $18 \%$ sucrose. Coronal, $40 \mu \mathrm{m}$-thick cryostat sections were prepared from the chemically fixed brains, and incubated for 24-48 hours at $4^{\circ} \mathrm{C}$ with a monoclonal antibody against parvalbumin (PV 235, Swant, Marly, Switzerland; www.swant.com) diluted 1: 10 '000 in $0.2 \%$ Triton-X 100 and 10\% horse serum, for 24-48 hours at $4^{\circ} \mathrm{C}$. They were washed in the same buffer and then incubated for 2 hours in the dark with goat anti-mouse IgG /Cy2 (1:200) (Jackson ImmunoResearch Inc., West Grove, 19390 PA, USA; www.jacksonimmuno.com) - to stain the primary antibody -, and with Streptavidin-Cy3 (1:1’000) (Jackson ImmunoResearch Inc.) - to detect the biotinylated dextran. After washing, sections at the relevant level were mounted and examined with a Zeiss Axiophot fluorescence microscope.

In three rats for each site, 30-50 $\mathrm{nl}$ of a $4 \%$ solution of Fluorogold (Fluorochrome LLC, Denver Co, 80218, USA) in saline were injected into one of the following regions: PAG (anteroposterior $-6.04 \mathrm{~mm}$; medio-lateral $=0.8 \mathrm{~mm}$; dorsoventral $=-5.6 \mathrm{~mm}$ ) and laterodorsal tegmental nucleus (anteroposterior $-8.72 \mathrm{~mm}$; medio-lateral $=0.8 \mathrm{~mm}$; dorsoventral $=-7 \mathrm{~mm}$ ). After sectioning, all slices containing the hypothalamus were incubated with the PV235 antibody and further prepared for indirect fluorescence microscopy as described above.

Archival material was evaluated to trace the connections to the PV1-nucleus (Tables 1 and 2). Previous experiments revealed the PV1-nucleus to be targeted with fair precision by the injection of peroxidase wheat-germ agglutinin (WGA-HRP) into the lateral hypothalamus (Moga et al., 1990). Likewise, retrograde tracing experiments from the midbrain have been reported by (Hurley et al., 1991) and (Herbert and Saper, 1992). In additional specimens, anterograde tracers were injected into the region containing the PV1-nucleus (see Table 3) and retrograde tracers (WGA-HRP; Fluorogold) in the ventrolateral PAG, laterodorsal tegmental nucleus or reticular formation.

\section{Mouse tracing experiments}

The expression of the enzyme Cre-recombinase in the parvalbumin-positive neurons of the PV1-nucleus of parvalbumin-Cre mice was demonstrated by breeding 129P2-Pvalb $<\mathrm{tm} 1$ (cre)Arbr>/J (Hippenmeyer et al., 2005) with B6;C3-Tg(CAG-DsRed,-EGFP)5Gae/J (Jackson laboratory, Bar Harbor, Maine) mice. In the resulting mice, only parvalbuminneurons expressing CRE-recombinase synthetise the green fluorescence protein, whereas all 
other neurons remains red. In these mice all of the parvalbumin-positive neurons in the PV1nucleus were EGFP-positive, and all of the EGFP-positive neurons in the PV1 were parvalbumin-immunoreactive. Furthermore, parvalbumin-immunostaining was routinely performed to detect the coexistence of this calcium-binding protein with the viral- or the retrograde (e.g. Fluorogold) tracers.

To study the projections of the PV-1 group in mice (25-35 g body weigth), the brains of parvalbumin-Cre mice (129P2-Pvalb<tm1 (cre)Arbr $>/ J)$ (Hippenmeyer et al., 2005) were stereotactically injected on the left side (or bilaterally) at coordinates anteroposterior Bregma $-1.5 \mathrm{~mm}$, medio-lateral $1.3 \mathrm{~mm}$ and dorsoventral $4.9-5.1 \mathrm{~mm}$ with the following Cre-dependent viral construct (Yonehara et al., 2011):

- Serotype 7 AAV EF1a-DIO-ChR2-mCherry-WPRE

In a few cases (Table 5), following Cre-dependent constructs were used:

- Serotype 7 AAV EF1a-DIO-ChR2c-2A-DsRed2-WPRE (e.g. 218/11 dx)

- AAV2/1.CAG.FLEX.EGFP.WPRE.bGH (502-12)

- $\quad$ AAV2/9.CAG.FLEX.EGFP.WPRE.bGH (503-12)

In the first construct, the mCherry was a fusion protein with channelrhodopsin, resulting in the red fluorescence being targeted to the outer membranes of the transfected cells. In the second construct, the $2 \mathrm{~A}$ linker segment was post-translationally deleted producing DsRed 2 protein that was localized to the cytoplasm of transfected neurons. The third and fourth construct leads to the expression of EGFP in Cre-positive cells. They were developed by the Allen-Institute and are available commercially from the Vector core at the University of Pennsylvania (http://www.med.upenn.edu/gtp/vectorcore/).

Four weeks later, the mice were transcardially perfused with $0.9 \% \mathrm{NaCl}$ and then with $4 \%$ PFA (see above). The brains were excised and processed as described above for rats, with the exception that $80 \mu \mathrm{m}$-thick (instead of $40 \mu \mathrm{m}$ ) sections were produced. These were then incubated with a rabbit parvalbumin-antiserum (PV25, Swant, Marly) and then processed for double fluorescence with a biotinylated secondary antibody and Streptavidin-CY2 or Cy3 (or Alexa 488). The sections were mounted and evaluated in either a fluorescence microscope (Zeiss Axiophot equipped with a Spot-camera (2M sampler), a Leica 6000 epifluorescence microscope equipped with a Hamamatsu C4742-95 camera, a Nanozoomer (Hamamatsu) or a confocal microscope (Leica CTR 6500).

Control tracing experiments-Five control experiments were performed to check if the projection of parvalbumin-immunoreactive structures located along the needle track to the PV1-nucleus (e.g. thalamic reticular nucleus, subthalamic nucleus, Zona incerta, medial hypothalamus) contributed endings to the terminal fields in the PAG (see Table 5, experiments 189/11, 415/12 and 416/12, 512/12, 513/12). Injections were performed at different mediolateral $(1 \mathrm{~mm}$ instead of $1.4 \mathrm{~mm}$ ) and dorsoventral (4.6 instead of 5.1) levels.

\section{Characterization of antibodies (Table 2)}

Antibodies against parvalbumin (PV235 and PV28/25, all Swant Inc., Marly, Switzerland) recognize only one band of $12 \mathrm{Kda} \mathrm{MW}$ in Western blots of brain extract in various species, including rat and mouse. They stain the brain in a pattern consistent with previous results (Celio, 1990) and do not produce staining in the brain of parvalbumin knock-out mice (Schwaller et al., 1999).

The CART-antibody (H-003-62, lot 00324) used to identify the cortically projecting subdivision of the Edinger-Westphal nucleus was acquired from Phoenix Pharmaceuticals 
(Burlingame, Ca). It was produced against synthetic peptides (amino acids 55-102) with no cross-reaction with similar peptides and its staining was inhibited by adsorption with the immunizing peptide $(1 \mu \mathrm{g} / \mu \mathrm{l})$. The staining pattern was consistent with previous localization results (Kirouac et al., 2006; Reeber and Sillitoe, 2011).

Photomicrographs-Images were imported in Photoshop and contrast, brightness and sharpness adapted, if necessary. The image stacks were prepared with the ImageJ software and the figures mounted with Adobe Illustrator.

\section{RESULTS}

\section{Experiments in rats}

Tracers that were injected into the ventrolateral part of the hypothalamus always extended beyond the borders of the parvalbumin-positive PV1-nucleus (Fig. 1 A, B). In the experiments described here, neurons in the PV-1 group did indeed take up the anterograde tracer biotinylated dextran (Fig. 1) or WGA-HRP or PHA-L, but other, unrelated nerve cells likewise transported the injected tracer. Hence, the resulting projections include more than would have been expected if only the PV-1 neurons had been targeted. A list of the terminal fields recognized in five such experiments is given in Table 3 and a schematic drawing of their localization in the mid- and hindbrain is found in Fig. 2B.

The known major targets of the lateral hypothalamus received anterogradely labeled axons, including the infralimbic cortex, the septum, the amygdala, the habenula, the lateral PAG (Fig. 1D and 2B) and the parabrachial nuclei (Fig. 2B). In three rats, terminal fields of labeled axons were observed also in the ventrolateral part of the PAG (highlighted with different colors (red, blue and green) in Fig. 2B.

To determine which of these sites might be specific targets of the PV1-nucleus, their inputs were retrogradely traced. Retrogradely labeled neurons in the PV1-nucleus were seen after injections into only the lateral and the ventrolateral PAG (Fig. 2 A and C, and Fig. 4E) and the laterodorsal tegmental nucleus (Figs. 3 and 4B) (see also Table 4) of archival and fresh material.

To determine the topography of the PV-1 projection to the rat PAG, we examined retrograde labeling after injections in the lateral or ventrolateral PAG, or in the reticular formation just outside the PAG, in 14 cases (the locations of the needle tips are indicated by red triangles in Fig. 2C). The injection of a retrograde tracer close to the PAG in the rostral midbrain (R266 and R655; level -5.65. Fig. 2B) did not lead to filling of the nerve cells in the PV1-nucleus (Table 4). Three injections of a retrograde/anterograde tracer into the pons just ventral to the dorsal tegmental nucleus (R570, R590 and R594. Fig. 2C) revealed only terminal fields (and a few perikarya) in the region occupied by the PV1-nucleus (Table 4). Only the 9 injections into the ventrolateral quadrant of the midbrain PAG (Fig. 2C), led to successful retrograde filling of many neurons in the PV1-nucleus (Table 4). Thus, a longitudinal column of successful retrograde injections in the PV1-nucleus was located in the rat ventrolateral PAG, and spanned a length of approximately $2 \mathrm{~mm}$ (Fig. 2C; level: -6.65 to -8.60 ).

As another example, Fig. 3A shows the result of a retrograde tracer injection close to the distal ventrolateral PAG and laterodorsal tegmental nucleus. Although other neurons in the lateral hypothalamus were also retrogradely labeled (Fig. 3 B, C, D), the characteristic PV-1 group was nevertheless discernible as an intensely-labeled cluster (Fig. 3 B-D). These findings are summarized in Table 4. 
Injections of retrograde tracer in areas such as the lateral septum, the central nucleus of the amygdale and the parabrachial nuclei which are known to receive inputs from the lateral hypothalamus, did not lead to labeling of the PV1-nucleus. The analysis of archival material after retrograde tracing was complemented and confirmed by an evaluation of freshlyprepared double stained specimens: neurons of the lateral hypothalamus that projected to the region of the laterodorsal tegmental region were indeed parvalbumin-positive. Fig. 4 reveals that when Fluorogold was injected close to the caudal part of the ventrolateral PAG / laterodorsal tegmental nucleus (Figs 4, A, B and E), it was transported back (Fig. 4C and 4G) to the small parvalbumin-positive neurons (Fig. 4D and 4H) in the PV1-nucleus of the lateral hypothalamus.

\section{Experiments in mice}

In the 129P2-Pvalb<tm1 (cre $)$ Arbr $>/ \mathrm{J} \times \mathrm{B} 6$;C3-Tg(CAG-DsRed,-EGFP)5Gae/J mouse, all parvalbumin-immunoreactive neurons of the PV1-nucleus expressed EGFP, thus confirming the presence of the Cre-recombinase in them (Fig 5 A-B). Notwithstanding the fact that the PV1-nucleus is near to other parvalbumin-immunoreactive cell groups, the mCherry-labeled neurons were almost entirely within the PV1-nucleus (Fig. 5, C-D and E-K). The PV1nucleus was often clearly visible as a compact cluster of cells emitting a red-fluorescent signal in the outermost part of the ventrolateral hypothalamus (Fig. $5 \mathrm{C}$ and D). Although not all of the parvalbumin-positive neurons of the PV1-nucleus were labeled by the viral construct (Fig. 5 D and E; see Table 5 for an approximation of the number of infected cells in each experiment), all of the virus-infected neurons were parvalbumin-positive. In most cases, small numbers of unrelated parvalbumin-positive neurons that lay along the track of the injection needle were labeled (Fig. 6A). These cells were located in the ventrobasal tip of the thalamic reticular nucleus, the medial edge of the globus pallidus, the subthalamic nucleus, or the lateral mammillary nucleus, as were scattered cells in the medial hypothalamus that send dendrites to the PV1-nucleus. The extent of this spread is summarized in Table 5. Control injections targeted to these diverse nuclei failed to label terminals in the ventrolateral part of the PAG (injections 189/11, 415/12 and 416/12; see Table 5).

Axons exited the rostral portion of the PV1-nucleus in the supraoptic commissure (Fig. 6B), its mid-region in the medial forebrain bundle, and its distal portion in dorsomedial direction (Fig. 5K). Fluorescent axons in the supraoptic commissure crossed the midline and ended in the contralateral region harboring the PV1-nucleus (Fig. 6B). Axons of neurons in the PV1nucleus that ran in the medial forebrain bundle lateral to the mammillary bodies traced a wide path through the ventral tegmental region. At the level of the interpeduncular nucleus, the fibers curved dorsally along the midline, converged around the fasciculus retroflexus (Fig. 6D) and were then concentrated in the region of the Edinger Westphal (EW) nucleus (Fig. 7A). A second component of the descending medial forebrain bundle ran into the ventromedial tegmentum at the level of the red nucleus, arched dorsolaterally and then entered the ventrolateral part of the PAG at the level of the oculomotor nuclei (Fig. 7 C-E).

In the PAG, the axons stemming from the PV1-nucleus terminated mainly ipsilaterally, ventrolateral to the aqueduct on the edge of the periaqueductal gray in the SU3 region (Paxinos and Franklin, 2001; Paxinos and Watson, 2009; Van Bockstaele et al., 1989) and more sparsely in the lateral region (Fig. 7 C, D and E-F, Fig 9 A-H). The dense cloud of terminals ventrolateral to the aqueduct formed a cylindrical column (PV1-CTF) (Fig. 7E and 9 A-D; G-H) whereas the lateral one was crescentic and contained scattered terminals (Fig. 7C, 9).

The "cylindrical terminal field" (PV1-CTF) was detectable first at level Bregma $-3.88 \mathrm{~mm}$ in the Atlas of Paxinos and Franklin (Paxinos and Franklin, 2001) and continued until level 
Bregma $-4.30 \mathrm{~mm}$ (rostral portion, Figs $7 \mathrm{E}, \mathrm{F} ; 9 \mathrm{~A}-\mathrm{D}$ and 11). After an interruption of approximately 150-200 $\mu \mathrm{m}$ (Figs. 2C, 9F and 11), the PV1-CTF continued from -4.56 to $4.84 \mathrm{~mm}$ (caudal portion, Figs $8 \mathrm{~A}-\mathrm{D}$ and $9 \mathrm{~F}-\mathrm{H}$ ), thus spanning a total length of approximately $1 \mathrm{~mm}$ (see details in Table 5, cases 64-66/12). The contralateral side also revealed the presence of a similar column of lower terminal density. The diameter of the cylindrical PV1-CTF in the rostral part was of approximately $0.2 \mathrm{~mm}$ (Figs. 7E and $9 \mathrm{~A}-\mathrm{D}$ ) and of the oval PV1-CTF in the caudal part of $0.4 \times 0.2 \mathrm{~mm}$ (Figs. $8 \mathrm{~A}-\mathrm{B}$ and $9 \mathrm{G}, \mathrm{H}$ ).

The terminals in the lateral quadrant first appeared approximately at level Bregma $-3.4 \mathrm{~mm}$ and continued until level $-4.7 \mathrm{~mm}$ in the Atlas of (Paxinos and Franklin, 2001). Both the PV1-CTF ventrolateral of the aqueduct and the lateral quadrant, in which terminal fields of the PV1-nucleus were observed, were discernible as parvalbumin-rich terminal areas in sections that had been immunohistochemically stained for parvalbumin (Fig. 7D, F). Qualitatively the density of terminals in the PV1-CTF seemed to correlate with the number of virus-infected cell bodies in the PV1-nucleus of different mice (See Table 5). A precise quantification (e.g. by measuring fluorescence intensities with a confocal microscope) was not attempted. The terminal field ventrolateral to the aqueduct was sometimes traversed by large blood vessels (Fig. 4 E-F).

At caudal levels between -4.56 and $-4.84 \mathrm{~mm}$ (Paxinos and Franklin, 2001), the PV1-CTF impinged on an uncharted parvalbumin-positive population of neurons (Figs. 8 A,B; 9 F-H; 11). At this level the cylindrical column flares out and transcends the borders of the PAG to invade the adjoining reticular formation (Fig. 9 F, G).

Injections of the tracer Fluorogold in this same quadrant at various levels of the PAG resulted in the retrograde filling of parvalbumin-positive neurons in the PV1-nucleus of rats (Fig. $2 \mathrm{C} ; 4 \mathrm{~A}-\mathrm{H}$ ) and mice (Fig. 10). While injecting at level -7.10 (Fig. 2C, gap at the level of the trochlear nucleus) in the rat, no neurons of the PV1-nucleus could be retrogradely filled with Fluorogold. In the mouse, neurons in the PV1-nucleus were retrogradely labelled, only when the rostral or caudal PV1-CTF were hit (Fig. 10).

The outermost portion of the crescentic quadrant of the lateral PAG receives few terminals from the PV1-nucleus (Fig. 7D). In sections that have been immunostained with antibodies against parvalbumin, this region is homogeneously labelled (Fig. 7E). We assume that the terminals originating from the PV1-nucleus constitute only a small proportion of the inputs to the lateral PAG. Embedded in the superficial, lateral portion of the caudal PAG are the large, parvalbumin-positive neurons of the mesencephalic trigeminal nucleus (Fig. 7F and $8 \mathrm{~B}$ ), which do not appear to be targeted by axons stemming from the PV1-nucleus. However, ultrastructural studies will be needed to confirm this impression.

The axon terminals coming from the PV1-nucleus were located more lateral than the CART(cocaine and amphetamine regulated transcript) neurons of the cortically projecting EWsubnucleus (Fig. 6E).

In some cases, in which large mCherry- labelled, parvalbumin-positive neurons were located more medially in the hypothalamus and in the lateral mammillary nucleus, terminals were identified in the dorsal tegmental nucleus (Fig. 6F). In two cases (189/11 and 218/11) the lateral mammillary nucleus was observed to contain a particularly large numbers of transduced neurons, and in those cases the dorsal tegmental nuclei were distinguished by the presence of intensely-labeled terminal fields. The terminals probably do indeed derive from the lateral mammillary nucleus, via the mammillio-tegmental tract (Cruce, 1977; Hayakawa and Zyo, 1990). 
In the tuberal hypothalamus, scattered large parvalbumin-positive neurons were seen with horizontal dendrites extending into the PV1-nucleus and were occasionally labelled with the viral construct. In control experiments that targeted only these neurons alone, no projection to the ventrolateral PAG was observed (case 416/12).

In two cases (189/11 and 64/12), which were distinguished by the presence of labeled neurons in the substantia nigra pars reticulata (SNr), inputs to the superior colliculus were particularly striking. The $\mathrm{SNr}$ is known to project to the superior colliculus (Cebrian et al., 2005), and since the inputs to the latter were observed only when cells of the former region were targeted, they probably derive from it. In some specimens, a group of intenselylabelled axons were seen that followed a vertical course through the fasciculus retroflexus (Fig. 6D) and then turned caudally in the ventral PAG. These axons appeared to stem mainly from the larger, most caudally-located neurons of the PV1-nucleus, but terminals in the region of the retroflex fascicle could not be identified with certainty.

The projections of the reticular thalamic nucleus are confined to the thalamus, whereas those of the medial segment of the globus pallidus extend to the lateral habenular nucleus (Herkenham and Nauta, 1977), the subthalamic nucleus and the substantia nigra (Carter and Fibiger, 1978). After an injection that left the medial segment of the pallidum unlabelled (237/11), only a few terminals (which possibly stemmed from the PV1- nucleus) were labeled in the lateral habenular nucleus. Hence, only a small proportion of the terminals in the latter structure originate from projections of the PV1-nucleus.

\section{DISCUSSION}

This hodological study has revealed that axons stemming from the elongated lateral hypothalamic PV1-nucleus terminate mainly ipsilaterally in a longitudinally-orientated cylindrical field ventrolateral to the aqueduct. The injection of antero-and retrograde tracers into the lateral hypothalamus has hitherto disclosed numerous connections with rostral and caudal structures (Barone et al., 1981; Berk and Finkelstein, 1982; Hosoya and Matsushita, 1980; Hosoya and Matsushita, 1981; Hurley et al., 1991; Kita and Oomura, 1981; Kita and Oomura, 1982; Moga et al., 1990; Saper et al., 1979; Veening et al., 1987; Villalobos and Ferssiwi, 1987; Wolf and Sutin, 1966). However spatially more targeted injections have revealed relatively few to be related to the PV1-nucleus. Indeed, our findings indicate that the hypothalamic PV1-nucleus projects almost exclusively to the PAG. We observed no projections either to rostral targets, such as the septum and the amygdala, or to caudal ones, such as the parabrachial nuclei. In the aforementioned tracer-studies, those that involved a broad spatial targeting of the labee ypothalamus, the PV1-nucleus - although not referred to as such - was sometimes preferentially. For example, Berk and Finkelstein (Berk and Finkelstein, 1982) observed terminals in the lateral and the ventrolateral PAG (case M15 in Fig. 2 I of their publication) after the injection of tritiated amino acids into the distal portion of what we now recognize as the PV1-nucleus. And after the injection of PHA-L into the ventrolateral subarea of the lateral hypothalamus, which encompasses the PV1-nucleus, Veening et al. (Veening et al., 1991) reported a similar distribution pattern of terminals ventrolateral to the aqueduct and to the dorsal raphe nucleus in rats (Fig. 5B in their publication). Using tritiated leucin as an anterograde tracer in cats, Holstege recognized a similar pattern of projection from the lateral hypothalamus to the PAG (Holstege, personal communication).

In the present study, anterograde tracing from the PV1-nucleus in both rats and mice revealed terminal fields predominantly ventrolateral to the aqueduct on the edge of the PAG (Fig. 2B and 11) (see also (Paxinos and Franklin, 2001). In mice, the anterograde labelling from the PV1-nucleus was more precise than in rats, thereby permitting the demonstration of 
a column of terminal fields (PV1-CTF) with a marked degree of topographical specificity in the PAG. This PV1-CTF is more medially located than the classical ventrolateral column that is reported in the literature (Bandler et al., 1991; Bandler and Shipley, 1994), is of smaller caliber and is axially restricted to the periphery of the PAG. The rostral target of the PV1-nucleus-derived PV1-CTF along the lateral edge of the SU3-region (Paxinos and Franklin, 2001) in the rostral, mesencephalic part of the PAG is unknown. Spatially, the location of the PV1-CTF corresponds to that of a clearly-demarcated parvalbumin-positive terminal field (Fig. 7F), thereby indicating that the immunoreactive endings stem mainly from the PV-1 nucleus. Some faintly parvalbumin-positive neurons are also recognized in this superficial Su3-region. The connections of the Su3 containing region in rats have been studied by several groups of investigators (Giolli et al., 1988; Leichnetz et al., 1987;

Maciewicz et al., 1975; Van Bockstaele et al., 1991; Van Bockstaele et al., 1989) and have been implicated in oculomotor control (Vertes and Martin, 1988), cortical activation and REM-sleep (Vertes, 1984), and, on the basis of the projection to the nucleus paragigantocellularis also in autonomic control (Van Bockstaele et al., 1989). In cats, a high density of ${ }^{3} \mathrm{HQNB}$ binding sites (pin-pointing putative muscarinic receptors), has been revealed at a similar location in the PAG (Fig. 1 in study by Gundlach (Gundlach, 1991). A projection from the SU3-region to the nucleus gigantocellulairs pontis, which is implicated in eye movements, has also been detected (Torigoe et al., 1986).

The caudal portion of the PV1-CTF in the metencephalic part of the PAG abuts on a previously unrecognized cluster of parvalbumin-positive neurons (Figs. 8 A, B and Fig. 9 F$\mathrm{H}$ ) at level -4.5 to -4.84 (Paxinos and Franklin, 2001). This area is referred to as the Substantia grisea centralis, pars ventralis in the atlas of (König and Klippel, 1974), and is delineated but not specifically named in (Paxinos and Franklin, 2001). In the publications that describe the parcellation of the PAG most comprehensively (Clements et al., 1987; Meller and Dennis, 1986; Ruiz-Torner et al., 2001), this region is not specifically mentioned, and is only alluded to but but cognized in the literature as a whole. In cats, chemical stimulation of this ith D-L-homocysteic acid leads to a decrease in both blood pressure and in the vasoconstrictor tone of the renal vascular bed (Carrive, 1991; Harper et al., 1991), as well as quiescence and hyporeactivity (Depaulis et al., 1994). In the same species, lesioning of this region has been likewise shown to elicit a decrease in bloodpressure as well as to prevent compensatory adjustments in arterial pressure during hemorrhaging (Ward and Darlington, 1987a; Ward and Darlington, 1987b). In the foreseeable future, tracer experiments involving the injection of Cre-dependent viral constructs into the distal PV1-CTF of parvalbumin-Cre mice (Hippenmeyer et al., 2005) will help to pin-point the targets of this anonymous group of nerve cells, which we will henceforth refer to as the "PV2-nucleus".

The short spatial interruption of the PV1-CTF that is revealed in rats and mice (see gap in Figs. 2C and 11) appears to be located at the level of the mesomere 2, a transverse, very slender preisthmic territory interposed between the oculomotor-and the trochlear nuclei (Puelles et al., 2012). The spatially coincidental localization of this gap in rats (Fig. 2C) and mice (Fig. 11) is striking.

The subdivision of the PV1-CTF into a rostral and a distal portion, accords with one of the hypothetical "longitudinal modules" of the PAG (Shipley et al., 1991). A cluster of intensely parvalbumin-positive neurons (the PV2-nucleus) occurs in its distal portion alone. The "longitudinal module" ventrolateral to the aqueduct, is therefore a chemoarchitectonically heterogeneous structure, which is consistent with the postulated functional heterogeneity of the rostrocaudal axis of other columns in the PAG (Bandler et al., 1991). 
One issue that could not be unambiguously clarified in the present study relates to possible differences in the projection targets of the anteriorly-located small neurons and the posteriorly-located large ones in the PV1-nucleus (Meszar et al., 2012). In rats, injections of fluorogold into the dorsolateral tegmental nucleus (caudal portion of the PV1-CTF) and into the Su3 region (rostral portion of the PV1-CTF) revealed retrograde staining of both the small and the large cells in the PV1-nucleus (Fig. 4). In mice, injections of the same tracer into either Su3-region (rostral PV1-CTF), or the PV2-nucleus (caudal PV1-CTF) of the PAG led to retrograde filling of the small as well as of the large neurons, thereby discounting any projection specificity.

Notwithstanding the very similar projection patterns ventrolateral to aqueduct in the PAG rats and mice (Figs. 2B and 11), some differences were observed between the two species. In rats, the PV1-CTF of terminals appears to run more caudally, and to extend to the zone of the laterodorsal tegmental nucleus. In mice, more rostrally-located structures, such as the Edinger-Westphal nucleus, received some terminals. These discrepancies could be attributable either to differences between the two species per se, or to those in the methodological approach.

In rats, the injection of classical tracers led to the labelling of many more neurons at the injection site, and the marker often spread out well beyond the intended target nucleus. For example, after the injection of a retrograde tracer into the laterodorsal tegmental nucleus, the marker may have diffused away as far as the caudal ventrolateral column of the PAG.

Although in mice the injection of the Cre-dependent viral construct resulted in a more specific targeting of the PV1-nucleus, to the exclusion of adjacent LHA-neurons, extraneous labelling of PV-immunoreative neurons along the needle track nonetheless consistently observed.

Apart from the discrepancies in projection pattern between rats and mice that arose from differences in the methodological approach, others may reflect species-specific peculiarities in physiology and behavior. For example, species differences in traits that are implicated for ventrolateral PAG-regions close to the PV1-CTF, e.g. vocalization, may be relevant.

Depending on their affective state, rats vocalize at two different ultrasonic frequencies: 20

$\mathrm{KHz}$ and $50 \mathrm{KHz}$. The chirps produced at $20 \mathrm{KHz}$ are implicated in situations that have a negative impact on the animals (Miczek et al., 1995), whereas the $50 \mathrm{KHz}$-ones are emitted in those with a positive influence (Knutson et al., 1998). Although mice can draw on a rich repertoire of ultrasonic emissions, vocalization does not appear to be related to their affective state (Portfors, 2007).

In conclusion, the findings of the present study confirm the existence of an elongated PV1nucleus within the lateral hypothalamus of rodents, and demonstrate that it sends out major projections to a column of terminal fields (PV1-CTF) located mainly ipsilateral, ventrolateral to the aqueduct on the edge of the PAG. Minor projections end in an identical location of the contralateral PAG, in the lateral habenular nucleus, the Edinger-Westphal nucleus, the reticular formation and the laterodorsal tegmental nucleus. By virtue of its projections to a topographically-restricted region ventrolateral to the aqueduct, the PV1nucleus may presumably exert discrete functions. Testable functions of the PV1-nucleus include a possible involvement in analgesic, defensive and sexual responses as in the autonomic adjustments that are indispensable for their successful expression. But other functions unrelated to those classically attributed to the periaqueductal gray, are not to be excluded. 


\section{Supplementary Material}

Refer to Web version on PubMed Central for supplementary material.

\section{Acknowledgments}

The authors would like to thank Profs. Tom Scammell (Harvard) and Joel Elmquist (now at the UTSW, Dallas) for their continuous help and recommendations, and Dr. Rienk Tuinhof (deceased) for evaluating the double-labelled rat specimens. They are also grateful to Viktoria Szabolcsi and Alessandro Bilella for their assistance with the analysis at the confocal microscope and to Marlene Sanchez for technical help. Anwesha Bhattacharyya (MSc) was involved in the initial experiments with rats. The graphic work of Figs. 2 and 11 were prepared by Beat Brüsch (illustrateur@illustrateur.ch / www.embryology.ch).

Several PhD-students and postdoctoral assistants in the laboratory of CS performed the experiments that yielded the archival material, and the authors are grateful to Karen M. Hurley, Horst Herbert and Margaret M. Moga for permitting us to utilize these specimens. The adeno-associate-viral constructs expressing cherry and red were received as a gift from Dr. K. Yonehara, who is collaborator in the lab of Dr. Botond Roska (FMI, Basle). Dr. Silvia Arber, FMI, Basle kindly provided the PV-Cre mice.

This study was financially supported by the Canton of Fribourg, the Swiss National Science Foundation (Grant Nr. 3100A0-113524), the Novartis Foundation and the USPHS (grants NS33987 and NS072337).

\section{Literature list}

Bandler, R.; Carrive, P.; Depaulis, A. Introduction: emerging principles of organization of the midbrain periaqueductal gray matter. In: Depaulis, A.; Bandler, R., editors. The midbrain periaqueductal gray matter. New York: Plenum; 1991. p. 1-10.

Bandler R, Shipley MT. Columnar organization in the midbrain periaqueductal gray: modules for emotional expression? Trends Neurosci. 1994; 17(9):379-389. [PubMed: 7817403]

Barone FC, Wayner MJ, Scharoun SL, Guevara-Aguilar R, Aguilar-Baturoni HU. Afferent connections to the lateral hypothalamus: a horseradish peroxidase study in the rat. Brain Res Bull. 1981; 7(1):75-88. [PubMed: 6974034]

Berk ML, Finkelstein JA. Efferent Connections of the lateral Hypothalamic Area of the Rat: An Autoradiographic Investigation. Brain Research Bulletin. 1982; 8:511-526. [PubMed: 6811106]

Bittencourt JC, Presse F, Arias C, Peto C, Vaughan J, Nahon JL, Vale W, Sawchenko PE. The melanin-concentrating hormone system of the rat brain: an immuno- and hybridization histochemical characterization. J Comp Neurol. 1992; 319(2):218-245. [PubMed: 1522246]

Carrive, P. Functional organization of PAG neurons controlling regional vascular beds. In: Depaulis, A.; Bandler, R., editors. The midbrain periaqueductal gray matter. New York: Plenum Press; 1991. p. $67-100$.

Carter DA, Fibiger HC. The projections of the entopeduncular nucleus and globus pallidus in rat as demonstrated by autoradiography and horseradish peroxidase histochemistry. J Comp Neurol. 1978; 177(1):113-123. [PubMed: 411809]

Cebrian C, Parent A, Prensa L. Patterns of axonal branching of neurons of the substantia nigra pars reticulata and pars lateralis in the rat. J Comp Neurol. 2005; 492(3):349-369. [PubMed: 16217789]

Celio MR. Calbindin D-28k and parvalbumin in the rat nervous system. Neuroscience. 1990; 35:375475. [PubMed: 2199841]

Chemelli RM, Willie JT, Sinton CM, Elmquist JK, Scammell T, Lee C, Richardson JA, Williams SC, Xiong Y, Kisanuki Y, Fitch TE, Nakazato M, Hammer RE, Saper CB, Yanagisawa M. Narcolepsy in orexin knockout mice: molecular genetics of sleep regulation. Cell. 1999; 98(4):437-451. [PubMed: 10481909]

Chi CC, Flynn JP. Neural pathways associated with hypothalamically Velicited attach behavior in cats. Science. 1971; 171(972):703-706. [PubMed: 5099720]

Clements JR, Madl JE, Johnson RL, Larson AA, Beitz AJ. Localization of glutamate, glutaminase, aspartate and aspartate aminotransferase in the $\mathrm{C}$ rat midbrain periaqueductal gray. Exp Brain Res. 1987; 67(3):594-602. [PubMed: 2888681] 
ruce JA. An autoradiographic study of the descending connections of the mammillary nuclei of the rat. J Comp Neurol. 1977; 176(4):631-644. [PubMed: 411808]

Depaulis A, Keay KA, Bandler R. Quiescence and hyporeactivity evoked lby activation of cell bodies in the ventrolateral midbrain periaqueductal gray of the rat. Exp Brain Res. 1994; 99(1):75-83. [PubMed: 7925798]

Giolli RA, Torigoe Y, Blanks RH. Nonretinal projections to the medial terminal accessory optic nucleus in rabbit and rat: a retrograde and anterograde transport study. J Comp Neurol. 1988; 269(1):73-86. [PubMed: 3361005]

Girard F, Meszar Z, Marti C, Davis FP, Celio MR. Gene-expression profiles in the parvalbuminimmunoreactive (PV1) nucleus of the mouse lateral hypothalamus. Eur J Neurosci. 2011; 34(12): 1934-1943. [PubMed: 22128821]

Guillery RW. Degeneration in the hypothalamic connexions of the albino rat. J Anat. 1957; 91(1):91115. [PubMed: 13405818]

Gundlach, AL. Regional subdivisions in the midbrain periaqueductal gray of the cat revealed by in vitro receptor autoradiography. In: Depaulis, A.; Bandler, R., editors. The midbrain periaqueductal gray matter. New York and London: Plenum Press; 1991. p. 449-464.

Hahn JD, Swanson LW. Distinct patterns of neuronal inputs and outputs of the juxtaparaventricular and suprafornical regions of the lateral hypothalamic area in the male rat. Brain Res Rev. 2010; 64(1):14-103. [PubMed: 20170674]

Hahn JD, Swanson LW. Connections of the lateral hypothalamic area juxtadorsomedial region in the male rat. J Comp Neurol. 2012; 520(9):1831-1890. [PubMed: 22488503]

Harper, RM.; Ni, H.; Zhang, J. Discharge relationship of periaqueductal gray neurons to cardiac and respiratory pattern during sleep and waking states. In: D, A.; B, R., editors. The midbrain periaqueductal gray matter. New York: Plenum press; 1991. p. 41-56.

Hayakawa T, Zyo K. Fine structure of the lateral mammillary projection to the dorsal tegmental nucleus of Gudden in the rat. J Comp Neurol. 1990; 298(2):224-236. [PubMed: 1698833]

Herbert H, Moga MM, Saper CB. Connections of the parabrachial nucleus with the nucleus of the solitary tract and the medullary reticular formation in the rat. J Comp Neurol. 1990; 293(4):540 580. [PubMed: 1691748]

Herbert H, Saper CB. Organization of Medullary Adrenergic and Noradrenergic Projections to the Periaqueductal Gray Matter in the Rat. The Journal of Comparative Neurology. 1992; 315:34-52. [PubMed: 1371780]

Herkenham M, Nauta WJ. Afferent connections of the habenular nuclei in the rat. A horseradish peroxidase study, with a note on the fiber-of-passage problem. J Comp Neurol. 1977; 173(1):123146. [PubMed: 845280]

Hippenmeyer S, Vrieseling E, Sigrist M, Portmann T, Laengle C, Ladle DR, Arber S. A developmental switch in the response of DRG neurons to ETS transcription factor signaling. PLoS Biol. 2005; 3(5):e159. [PubMed: 15836427]

Holstege G. Anatomical study of the final common pathway for vocalization in the cat. J Comp Neurol. 1989; 284(2):242-252. [PubMed: 2754035]

Hosoya Y, Matsushita M. Cells of origin of the descending afferents to the lateral hypothalamic area in the rat, studied with the horseradish peroxidase method. Neurosci Lett. 1980; 18(3):231-236. [PubMed: 6189023]

Hosoya Y, Matsushita M. Brainstem projections from the lateral hypothalamic area in the rat, as studied with autoradiography. Neurosci Lett. 1981; 24(2):111-116. [PubMed: 6166908]

Hurley KM, Herbert H, Moga MM, Saper CB. Efferent projections of the infralimbic cortex of the rat. J Comp Neurol. 1991; 308(2):249-276. [PubMed: 1716270]

Kirouac GJ, Parsons MP, Li S. Innervation of the paraventricular nucleus of the thalamus from cocaine- and amphetamine-regulated transcript (CART) containing neurons of the hypothalamus. J Comp Neurol. 2006; 497(2):155-165. [PubMed: 16705679]

Kita H, Oomura Y. Reciprocal connections between the lateral hypothalamus and the frontal complex in the rat: electrophysiological and anatomical observations. Brain Res. 1981; 213(1):1-16. [PubMed: 6165439] 
Kita H, Oomura Y. An HRP Study of the Afferent Connections to Rat Lateral Hypothalamic Region. Brain Research Bulletin. 1982; 8:63-71. [PubMed: 6173104]

Knutson B, Burgdorf J, Panksepp J. Anticipation of play elicits high-frequency ultrasonic vocalizations in young rats. J Comp Psychol. 1998; 112(1):65-73. [PubMed: 9528115]

König, JFR.; Klippel, RA. The rat brain: a stereotaxic atlas of the forebrain and lower parts of the brain stem. New York: Robert E. Krieger Publishing Co, Inc; 1974.

Leichnetz GR, Hardy SG, Carruth MK. Frontal projections to the region of the oculomotor complex in the rat: a retrograde and anterograde HRP study. J Comp Neurol. 1987; 263(3):387-399. [PubMed: 2822775]

Maciewicz RJ, Kaneko CR, Highstein SM, Baker R. Morphophysiological identification of interneurons in the oculomotor nucleus that project to the abducens nucleus in the cat. Brain Res. 1975; 96(1):60-65. [PubMed: 1175005]

Meller ST, Dennis BJ. Afferent projections to the periaqueductal gray in the rabbit. Neuroscience. 1986; 19(3):927-964. [PubMed: 3796822]

Meszar Z, Girard F, Saper CB, Celio MR. The lateral hypothalamic parvalbumin-immunoreactive (PV1) nucleus in rodents. J Comp Neurol. 2012; 520:798-815. [PubMed: 22020694]

Miczek KA, Weerts EM, Vivian JA, Barros HM. Aggression, anxiety and vocalizations in animals: GABAA and 5-HT anxiolytics. Psychopharmacology (Berl). 1995; 121(1):38-56. [PubMed: 8539340]

Moga MM, Herbert H, Hurley KM, Yasui Y, Gray TS, Saper CB. Organization of cortical, basal forebrain, and hypothalamic afferents to the parabrachial nucleus in the rat. J Comp Neurol. 1990; 295(4):624-661. [PubMed: 1694187]

Paxinos, G.; Franklin, KBJ. The mouse brain in stereotaxic coordinates. San Diego, London, Boston: Academic Press; 2001.

Paxinos, G.; Watson, C. The rat brain in stereotaxic coordinates. San Diego: Elsevier Inc; 1999.

Paxinos, G.; Watson, CW. The rat brain in stereotaxic coordinates. San Diego: Academic Press; 2009.

Peyron C, Tighe DK, van den Pol AN, de Lecea L, Heller HC, Sutcliffe JG, Kilduff TS. Neurons containing hypocretin (orexin) project to multiple neuronal systems. J Neurosci. 1998; 18(23): 9996-10015. [PubMed: 9822755]

Portfors CV. Types and functions of ultrasonic vocalizations in laboratory rats and mice. J Am Assoc Lab Anim Sci. 2007; 46(1):28-34. [PubMed: 17203913]

Puelles, E.; Martinez de la, M.; Torre, M.; Watson, CW.; Puelles, L. Midbrain. In: Watson, CW.; P, G.; Puelles, L., editors. The mouse nervous system. Amsterdam: Elsevier; 2012. p. 337-359.

Reeber SL, Sillitoe RV. Patterned expression of a cocaine- and amphetamine-regulated transcript peptide reveals complex circuit topography in the rodent cerebellar cortex. J Comp Neurol. 2011; 519(9):1781-1796. [PubMed: 21452228]

Ruiz-Torner A, Olucha-Bordonau F, Valverde-Navarro AA, Martinez-Soriano F. The chemical architecture of the rat's periaqueductal gray based on acetylcholinesterase histochemistry: a quantitative and qualitative study. J Chem Neuroanat. 2001; 21(4):295-312. [PubMed: 11429271]

Saper CB, Loewy AD, Swanson LW, Cowan WM. Direct hypothalamo-autonomic connections. Brain Res. 1976; 117(2):305-312. [PubMed: 62600]

Saper CB, Swanson LW, Cowan WM. An autoradiographic study of the efferent connections of the lateral hypothalamic area in the rat. J Comp Neurol. 1979; 183(4):689-706. [PubMed: 105019]

Schwaller B, Dick J, Dhoot G, Carroll S, Vrbova G, Nicotera P, Pette D, Wyss A, Bluethmann H, Hunziker W, Celio MR. Prolonged contraction-relaxation cycle of fast-twitch muscles in parvalbumin knockout mice. Am J Physiol. 1999; 276(2 Pt 1):C395-C403. [PubMed: 9950767]

Shipley, MT.; Ennis, M.; Rizvi, TA.; Behbehani, MM. Topographical specificity of forebrain inputs to the midbrain peraqueductal gray: evidence for discrete longitudinally organized columns. Depaulis, A.; Bandler, R., editors. New York and London: Plenum Press; 1991.

Swanson, LW. Brain Maps: structure of the rat brain. Amsterdam: Elsevier; 2004.

Torigoe Y, Blanks RH, Precht W. Anatomical studies on the nucleus reticularis tegmenti pontis in the pigmented rat. II. Subcortical afferents demonstrated by the retrograde transport of horseradish peroxidase. J Comp Neurol. 1986; 243(1):88-105. [PubMed: 3512625] 
Van Bockstaele EJ, Aston-Jones G, Pieribone VA, Ennis M, Shipley MT. Subregions of the periaqueductal gray topographically innervate the rostral ventral medulla in the rat. J Comp Neurol. 1991; 309(3):305-327. [PubMed: 1717516]

Van Bockstaele EJ, Pieribone VA, Aston-Jones G. Diverse afferents converge on the nucleus paragigantocellularis in the rat ventrolateral medulla: retrograde and anterograde tracing studies. J Comp Neurol. 1989; 290(4):561-584. [PubMed: 2482306]

VanderHorst VG, Ulfhake B. The organization of the brainstem and spinal cord of the mouse: relationships between monoaminergic, cholinergic, and spinal projection systems. J Chem Neuroanat. 2006; 31(1):2-36. [PubMed: 16183250]

Veening, G.; Buma, P.; Ter Horst, GJ.; Roeling, TAP.; Luiten, PGM.; Nieuwenhuys, R. Hypothalamic projections to the PAG in the rat: topographical, Vimmuno-electronmicroscopical and functional aspects. In: Depaulis, A.; Bandler, R., editors. The midbrain periaqueductal gray matter. New York and London: Plenum Press; 1991.

Veening JG, Lie ST, Geeraedts LMG, Nieuwenhuys R. A Topographial Analysis of the Origin of some Efferent Projections from the Lateral Hypothalamus Area in the Rat. Neuroscience. 1987; 22(2):537-551. [PubMed: 2823175]

Vertes RP. Brainstem control of the events of REM sleep. Prog Neurobiol. 1984; 22(3):241-288. [PubMed: 6382442]

Vertes RP, Martin GF. Autoradiographic analysis of ascending projections from the pontine and mesencephalic reticular formation and the median raphe nucleus in the rat. J Comp Neurol. 1988; 275(4):511-541. [PubMed: 3192756]

Villalobos J, Ferssiwi A. The differential descending projections from the anterior, central and posterior regions of the lateral hypothalamic area: an autoradiographic study. Neurosci Lett. 1987; 81(1-2):95-99. [PubMed: 2447527]

Ward DG, Darlington DN. A blood pressure lowering effect of lesions of the caudal periaqueductal gray: relationship to basal pressure. Brain Res. 1987a; 423(1-2):373-377. [PubMed: 3676815]

Ward DG, Darlington DN. Lesions of the caudal periaqueductal gray prevent compensation of arterial pressure during hemorrhage. Brain Res. 1987b; 407(2):369-375. [PubMed: 3567651]

Wolf G, Sutin J. Fiber degeneration after lateral hypothalamic lesions in the rat. J Comp Neurol. 1966; 127(2):137-156. [PubMed: 5962682]

Yonehara K, Balint K, Noda M, Nagel G, Bamberg E, Roska B. Spatially asymmetric reorganization of inhibition establishes a motion-sensitive circuit. Nature. 2011; 469(7330):407-410. [PubMed: 21170022] 


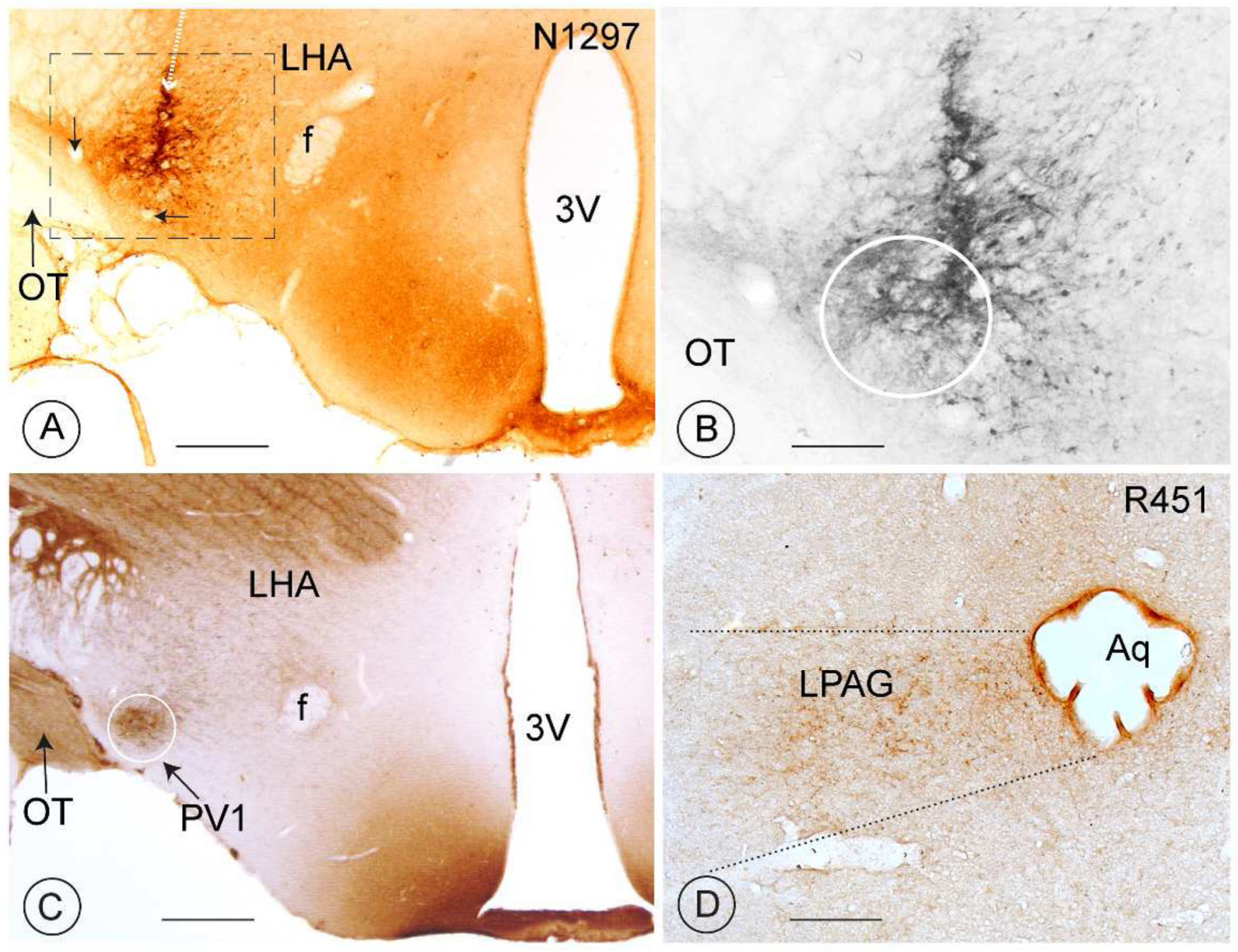

Fig. 1. Anterograde tracing from the PV1-nucleus in rats

A, B: In rats, biotinylated-dextran, was used as an anterograde tracer. The tip of the micropipette (represented by the white broken arrow in A) deposited the tracer in a region that includes the PV1-nucleus (white circle in B; injection N 1297). The results of this and of similar experiments were used in the compilation of Tables 1 and 2. The two small black arrows point to vessels that can be observed also in figure $5 \mathrm{C}$ (white arrows), cut at a similar level in the rat brain.

C: Immunohistochemical revelation of parvalbumin to indicate the location and size of the PV-nucleus at a level corresponding to Fig. 1A. Notice the paucity of other parvalbuminpositive elements in the close surroundings of the PV1-nucleus.

D: A nterograde PHAl-tracing of axon terminals stemming from neurons that were injected in the lateral hypothalamic region, which includes the PV1-nucleus (injection 451, see also Table 3). These axon terminals are widely distributed throughout the cross-sectional area of the lateral PAG.

Scale bars in A and C: $1 \mathrm{~mm}$ and in B and D: $0.5 \mathrm{~mm}$ 


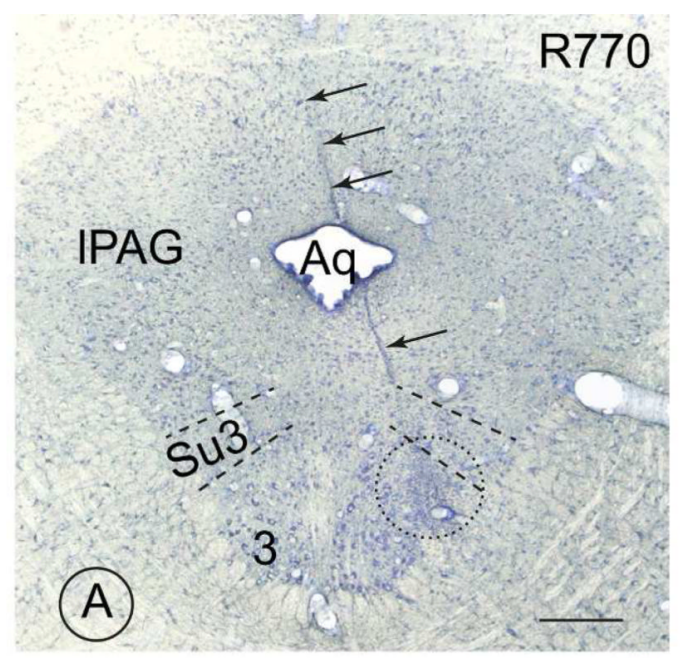

PB LDTg

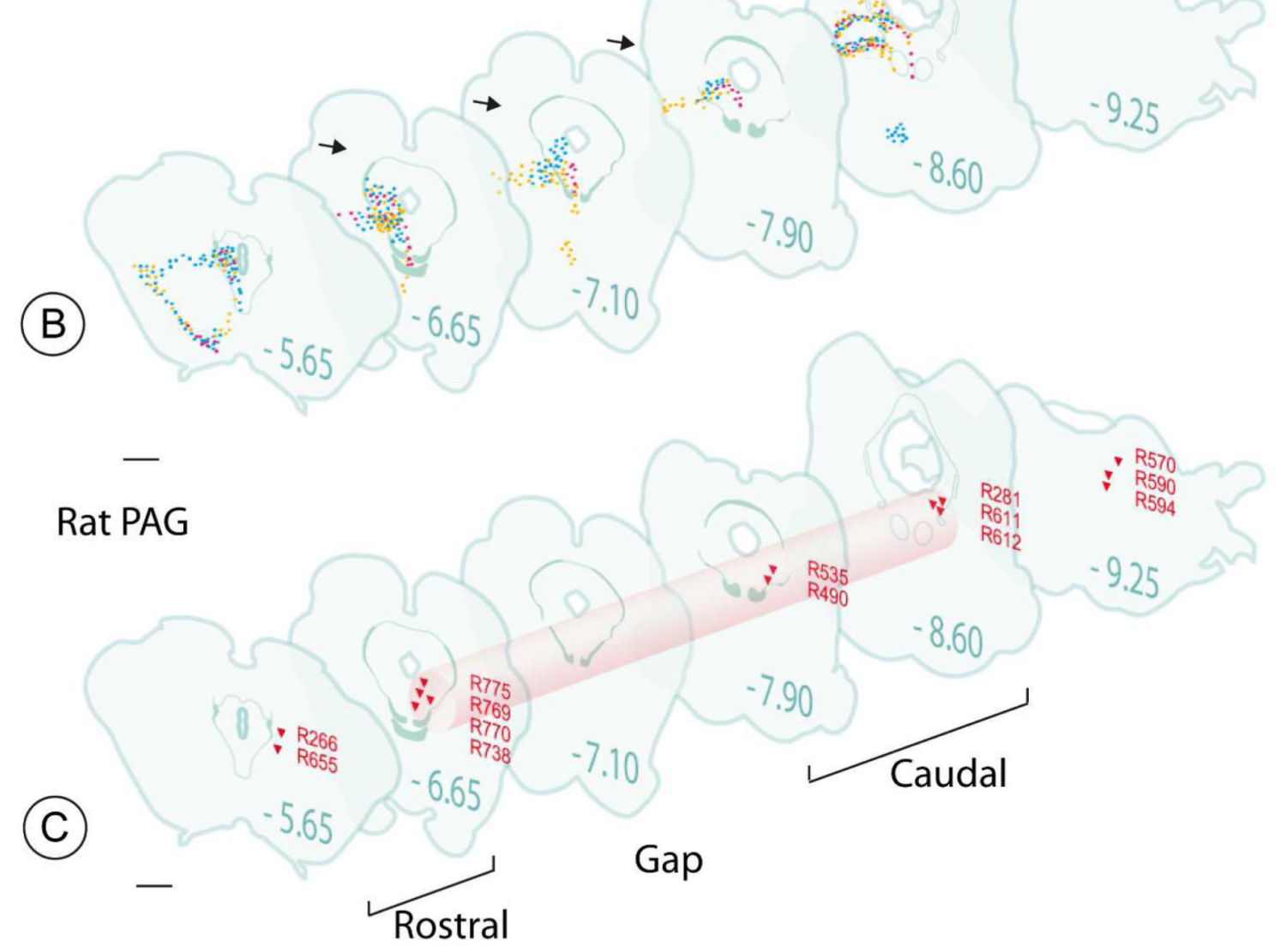

Fig. 2. Anterograde tracing from the lateral hypothalamus and retrograde tracing from the rat PAG (archival material)

A: The track left by the micropipette that deposited the WGA-peroxidase (injection R770) ventrolateral to the aqueduct is marked with black arrows. The approximate portion ventrolateral to the aqueduct that was exposed to this retrograde tracer is encircled (stippled circle). Notice the proximity of the pipette tip to the Su3 region. Scale bar $0.8 \mathrm{~mm}$. B: Axon terminals (small colored points) are depicted. Three anterograde-tracing experiments are jointly summarized (red: injection R189; yellow: injection R93 and blue: injection R451, (see Table 3)). Note the similarities between the three specimens in the distribution patterns of the terminals ventrolateral to the aqueduct (short arrows at levels 
$-6.65,-7.10$ and -7.90$)$, in the parabrachial nuclei (PB) and the dorsolateral tegmental nucleus (LDTg). However, most of the terminals in these last two structures apparently do not come from the PV-1 cell group.

$\mathrm{C}$ : The location of the needle tip in fourteen retrograde tracing experiments is indicated by red triangles. Only nine injections located between level -6.65 and -8.60 succeeded in filling retrogradely neurons in the PV1 (see table 4, e.g. injection R770, also depicted in Fig. 2A). These injection sites occupy a virtual "column" (light red) located ventrolateral to the aqueduct and composed of a rostral and a caudal part interrupted approximately at level -7.10 by a short gap. Drawing modified from (Swanson, 2004). Scale bar $1.5 \mathrm{~mm}$. 

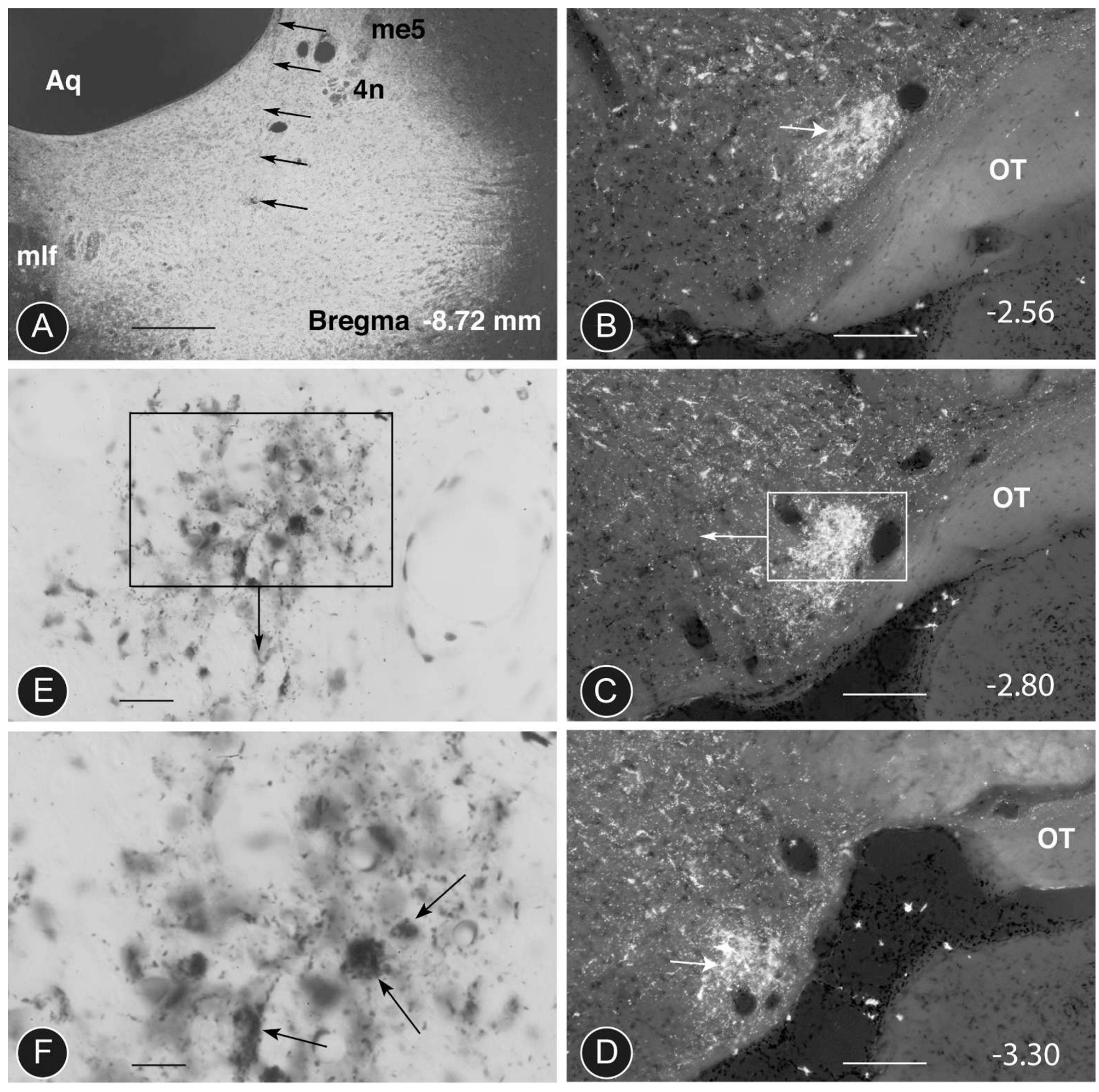

Fig. 3. WGA-HRP retrograde tracing from the distal PAG in the rat

A: Dark-field image of a WGA-peroxidase injection into the caudal PAG at level -8.72 according to (Paxinos and Watson, 1999). The track left by the micropipette is indicated with thin black arrows. The tip of the micropipette is located within the ventrolateral PAG at the level of the LDTg (fifth arrow). Injection 490 (Table 4). Scale bar $0.25 \mathrm{~mm}$.

B, C, D: Retrograde filling of neurons in the PV1-nucleus of the same animal at three different levels $(-2.56,-2.80$ and -3.30$)$. In addition to the cells in the PV1-nucleus (arrows), other retrogradely labelled neurons are scattered throughout the lateral hypothalamic area. Scale bar $0.3 \mathrm{~mm}$. 
E, F: Bright-field images of the same PV1-nucleus revealing the presence of some retrogradely-labelled neurons of different sizes (arrows in F) and considerable axonal labeling (small spots) suggesting a reciprocal projection. Counterstaining with Nissl stain. Scale bar $25 \mu \mathrm{m}$. 

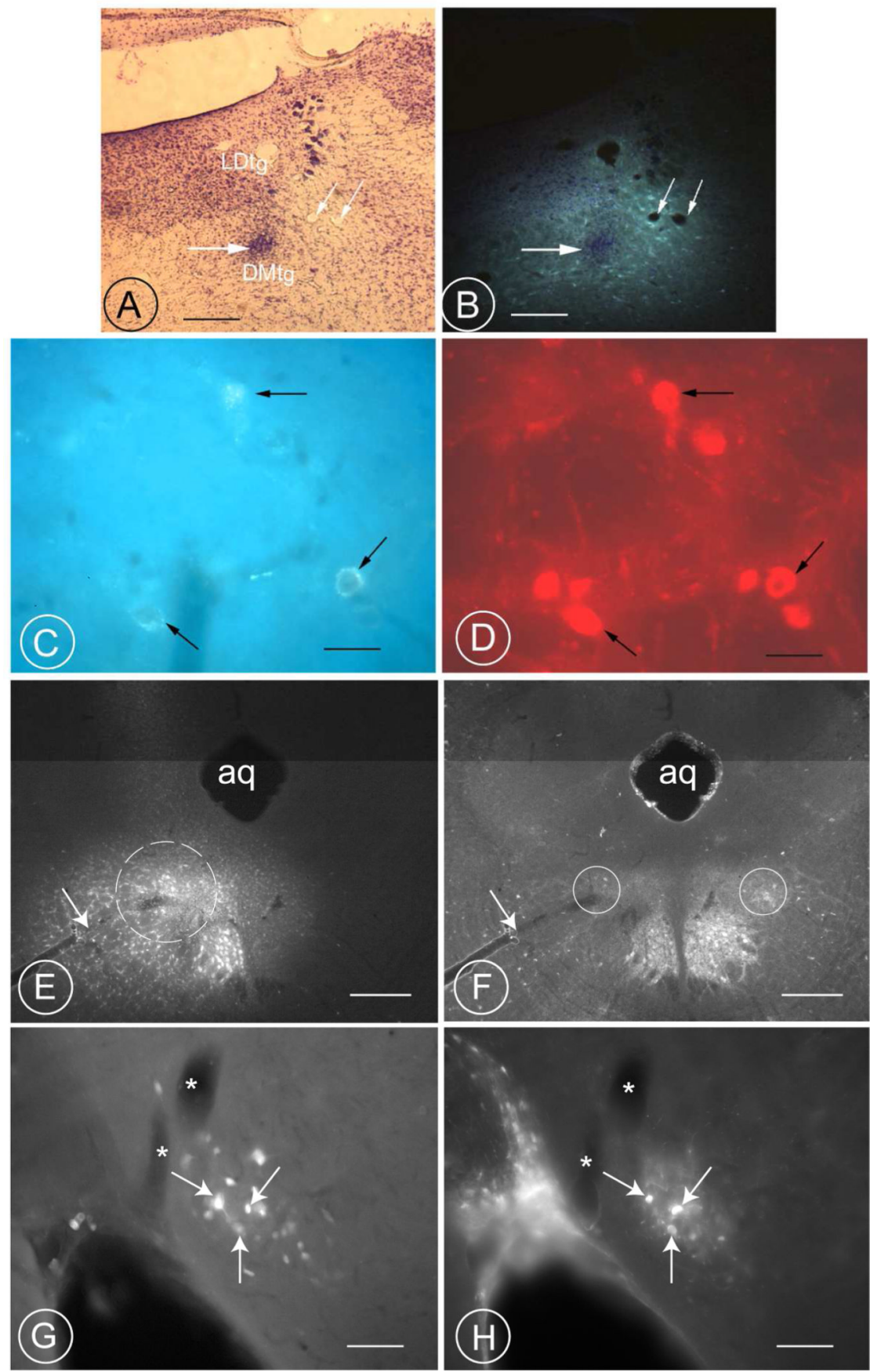

Fig. 4. Retrogradely labeled neurons in the PV1 nucleus are parvalbumin-positive, demonstrating their projection to the PAG and the LDTg in rats

A, B: Fluorogold was injected into the tegmental area at Bregma level -9.16. The thick, horizontal arrow in A indicates the location of the needle tip. The same region is depicted in $\mathrm{B}$ after illumination with ultraviolet light. Under these illumination conditions, the fluorogold label is seen to have diffused from the needle tip into the laterodorsal tegmental nucleus. The slender arrows in A and B denote cross-sections through two landmark vessels. Scale bar $0.3 \mathrm{~mm}$.

C, D: Three retrogradely-labelled neurons (arrows in C) are visible within the ipsilateral PV1- nucleus of the same animal (Bregma-level -3.30). In D, the same section, incubated 
with an antiserum against parvalbumin, reveals these three neurons (arrows) to be immunoreactive for this marker protein. Scale bar $20 \mu \mathrm{m}$.

E-F: Fluorogold applied in the region ventrolateral to the rat PAG (dashed circle in E), including the region characterized by a high concentration of parvalbumin-positive terminals (circle in F). Scale bars, $0.3 \mathrm{~mm}$. The arrow in $\mathrm{E}$ and $\mathrm{F}$ points to a large vessel passing through the parvalbumin-rich region..

G-H: Retrogradely fluorogold filled neurons are concentrated in the region of the PV1nucleus (Fig. G, DAPI-filter) and some of them (arrows) express parvalbumin immunoractivity (H; Cy3-Filter). Both large and small cells are retrogradely filled (G). Notice the presence of two large vessels in the vicinity of the PV1-nucleus (asterisks). Scale bar $75 \mu \mathrm{m}$. A magenta-green version of this image is included as supplementary figure number 1 . 

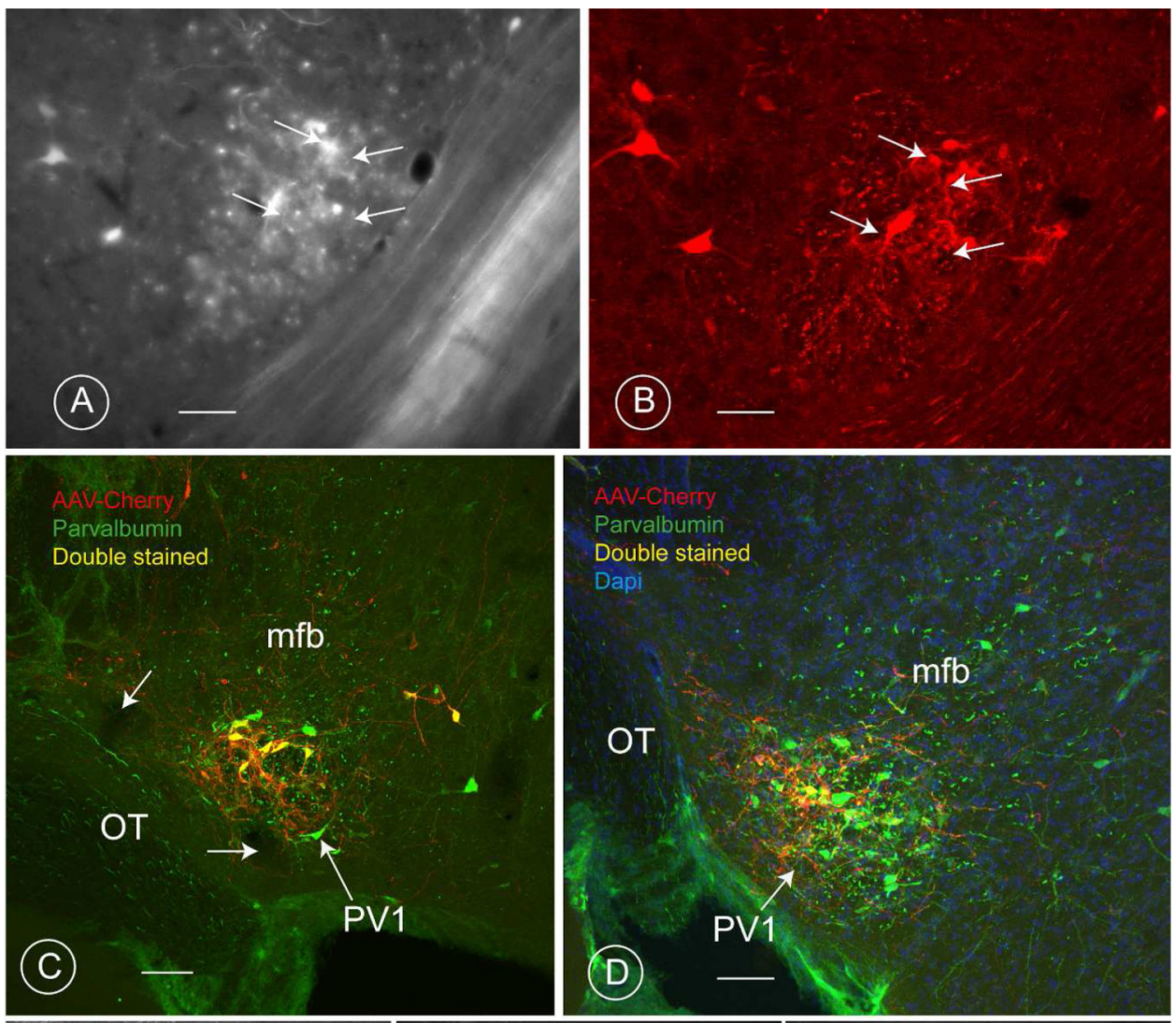

Double stained

Dapi

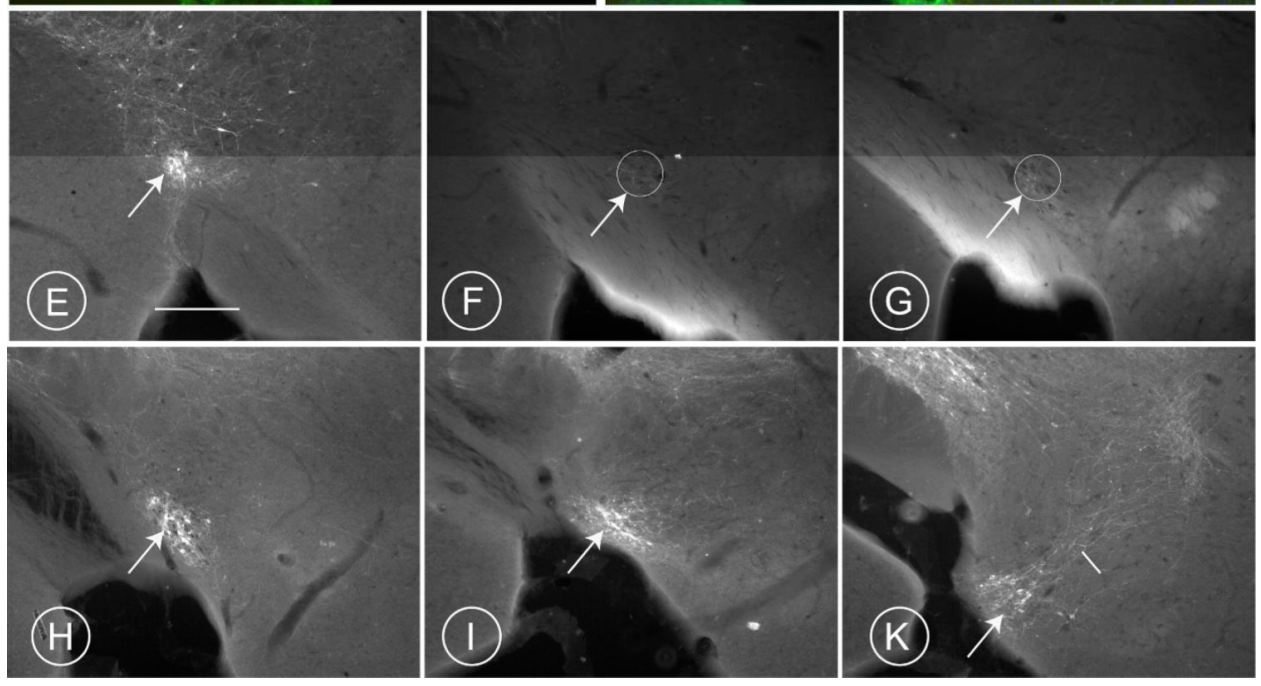

Fig. 5. Adeno associated viral construct injected in the PV1-nucleus of the mouse

A-B: Breeding PV-Cre mice with EGFP-floxed mice gave rise to offspring in which all the neurons in the PV1-nucleus are expressing GFP (A; fluorescent microscopy) were also parvalbumin-positive (B; confocal microscopy). Some double labelled cells are indicated by white arrows. Scale bars $30 \mu \mathrm{m}$.

C, D: The Cre-dependent adeno-associated-virus-mCherry construct has been taken up by some of the cells (red) in the PV1-nucleus, which are co-labelled with a Cy2-tagged antibody against parvalbumin (green). Nearly all of the red (mCherry labeled) neurons also are green PV1 cells, so the concurrent fluorescence signals appear yellow. However, a few AAV-infected cells emit only a red signal, owing to the poor penetration of the PV antibody 
through this $(80 \mu \mathrm{m})$ thick sections. The image in $\mathrm{C}$ (experiment 218), is taken at the posterior-level of the PV1-nucleus; that in D at its caudal extremity. The two white arrows in $\mathrm{C}$ indicate vessels that can be observed also in figure 1B (small black arrows), cut at a similar level in the rat brain. Scale bars: $30 \mu \mathrm{m}$.

E-K: Six consecutive coronal sections at distances of approximately $130 \mathrm{~mm}$ from each other through the region of the mouse PV1-nucleus from proximal (E) to distal (L) (injection 188/11). The AAV-cherry positive group of neurons in the PV1 is highlighted with an arrow. The intermediate portion of the PV1-nucleus $(F, G)$ remained unlabelled in this experiment. The small white line in K points to streaming axons. Scale bar for these 6 images: $0.2 \mathrm{~mm}$. A magenta-green version of this image is included as supplementary figure number 2 . 

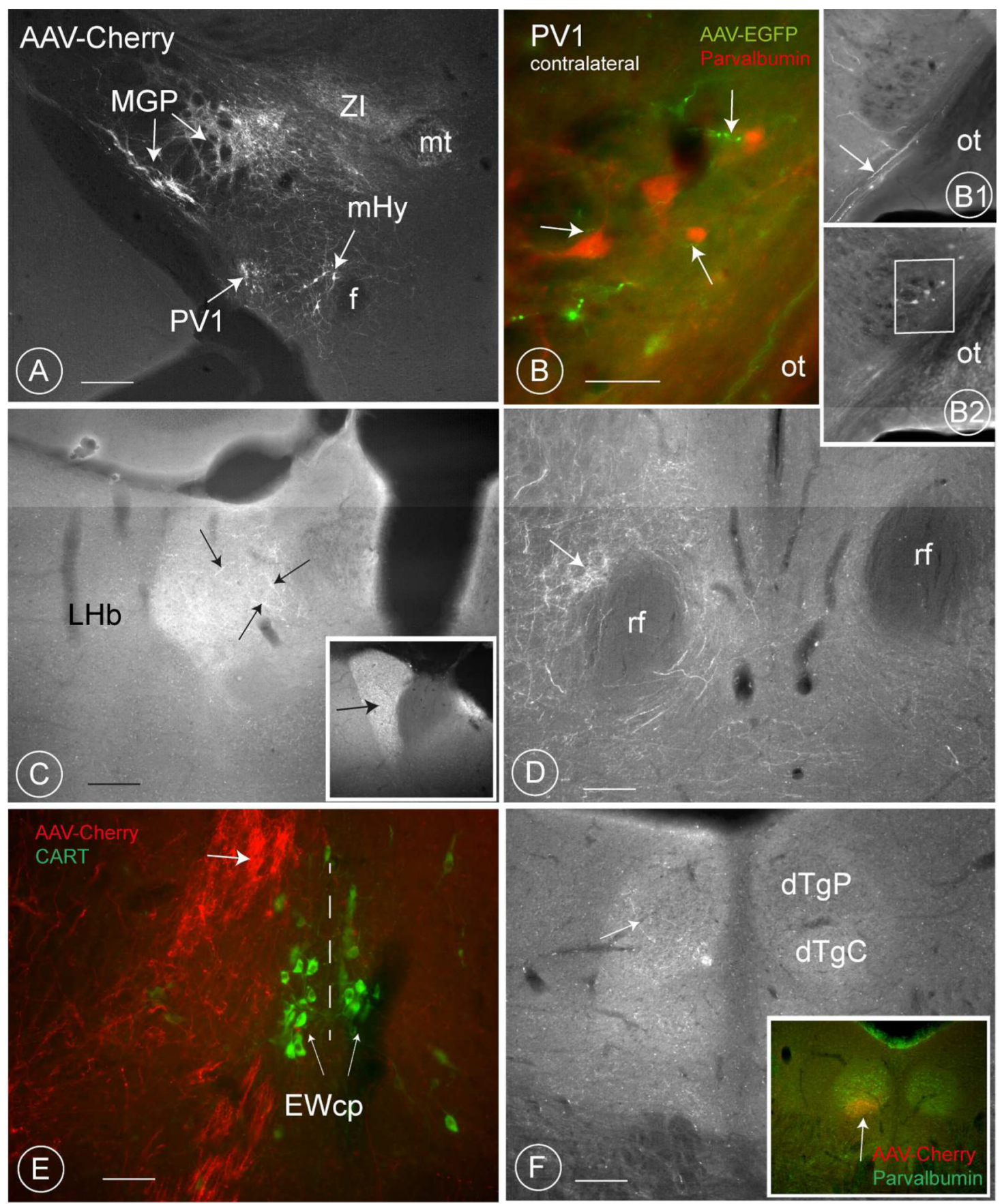

Fig. 6. AAV- co-labelling of other structures in the mouse diencephalon

A: In addition to the PV1-nucleus, also neurons in the medial globus pallidus (MGP, also called the entopeduncular nucleus), the subthalamic nucleus (STh) the reticular nucleus of the thalamus (NRTh) and the Zona incerta (in the picture only axons are visible for these two structures; cell bodies are at another level) took up the viral construct (see Table 5 for details). Injection 64/12. Scale bar $0.2 \mathrm{~mm}$.

B: Contralateral projection of the PV-1 neurons. EGFP-positive axons course in the supraoptic decussation (black arrow) and green terminals (white arrows), are close to parvalbumin-positive PV1 -neurons (red) of the opposite side. 
B1 and B2: are the original images from which the merged image B was generated. The white arrow in B2 indicate axons in the supraoptic decussation and the rectangle in B2 the boundaries of the merged Fig. B. Injection 502/12. Scale bar in B: $30 \mu \mathrm{m}$. Scale bars in B1 and B2, $0.2 \mathrm{~mm}$.

C: Some endings visible in the ipsilateral lateral habenular nucleus (experiment 237/12). In experiments with inadvertent labelling of the medial globus pallidus, the density of terminals is much higher (inset, injection 238/12). Scale bar $0.2 \mathrm{~mm}$

D: Axons and probably terminals deriving perhaps from the PV1 in the ipsilateral region around the retroflex fascicle. The axons then converge medially and are visible as a compact bundle adjacent to the $\mathrm{EW}$, some sections later (6E). Scale bar $0.2 \mathrm{~mm}$

E: A compact bundle of axons in the region of the EW (white arrow. The section is counterstained with an antibody to CART, a marker of the cortically projecting part of the EW-nucleus (EWcp, thin arrows). Terminals are located slightly more laterally (arrow). The vertical dashed line represents the midline. Injection 64/12. Scale bar $50 \mu \mathrm{m}$.

F: Terminals are sometimes present in the mediodorsal tegmental nucleus (MdTG). Their number increases drastically when the lateral mamillary nucleus is inadvertently co-stained (inset, white arrow). Injection 238/11. Scale bar $0.2 \mathrm{~mm}$. A magenta-green version of this image is included as supplementary figure number 3 . 

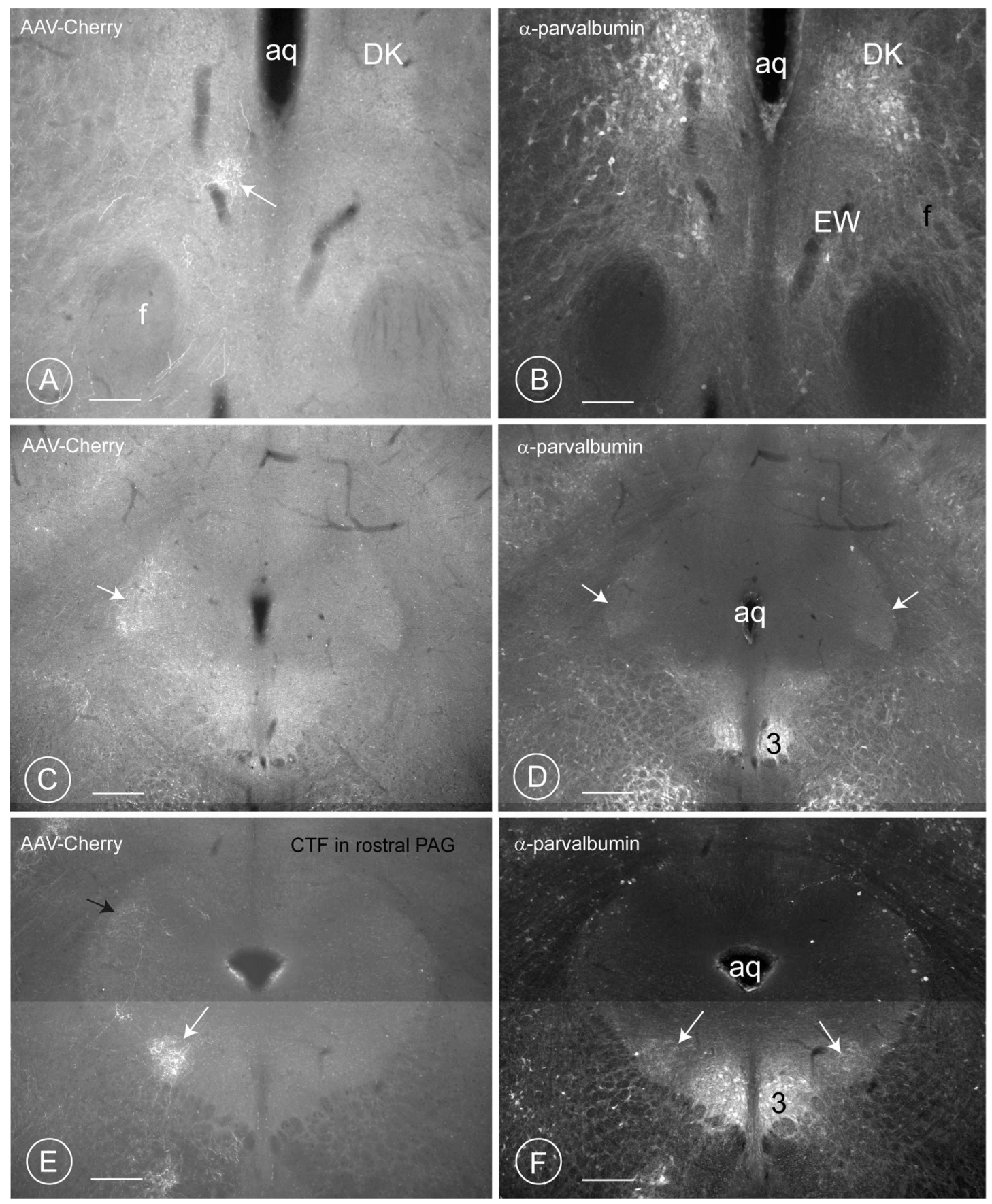

Fig. 7. Distribution of terminal fields in the rostral PAG of mice

A - F: Three different levels of the mesencephalic PAG are reproduced, from the most rostral (Bregma -2.54), to the most caudal (Bregma -4.30). Figures A, C and E represent the terminal fields of the AAV-Cherry positive projections stemming from the PV1-nucleus. Figures B, D and $\mathrm{F}$ show the immunohistochemical revelation of the calcium bindingprotein parvalbumin.

A-B: the first terminal field of axons deriving from the PV1-nucleus (arrow in A) occurs at the level of the Edinger-Westphal nucleus (B), below the nucleus of Darkschewitz (DK, in $\mathrm{A}$ and $\mathrm{B})$. 
C-D: The second terminal field of AAV-cherry-positive axons deriving from the PV1nucleus is observed in the outer shell of the lateral portion of the PAG (arrow in D; level -3.88 in (Paxinos and Franklin, 2001)), which coincides with a cloud of parvalbuminpositive endings (arrow in E). Only scattered terminals from the PV1-are observed (D), indicating that most of the parvalbumin positive endings in this region (E) have another source. The parvalbumin-positive neurons of the oculomotor nucleus (3) are visible ventromedially. Injection 64/12.

E-F: The third, most prominent terminal field is encountered ventrolateral to the aqueduct (white arrow) at the level of the oculomotor nucleus (3 in FFig. 5F). This terminal field forms a longitudinally-orientated cylinder, which spans approximately $450 \mu \mathrm{m}$ in length (see also schematic drawing in Fig. 11). Compare this image with that of the retrograde injection in the rat PAG (Fig. 2B). Axons enter this fluffy aggregate of terminals from below and some may come from laterally. The black arrow in Fig. 5E indicates scattered axons in the lateral PAG. Switching of the filter to visualize the parvalbumin-immunostaining (Fig. 5F) reveals the axons of the PV1-nucleus to terminate in a territory rich in parvalbumin-positive endings, harboring only a few parvalbumin-positive neurons (bilateral white arrows in F) (injection 66/12, Table 5). Scale bars $0.3 \mathrm{~mm}$. 

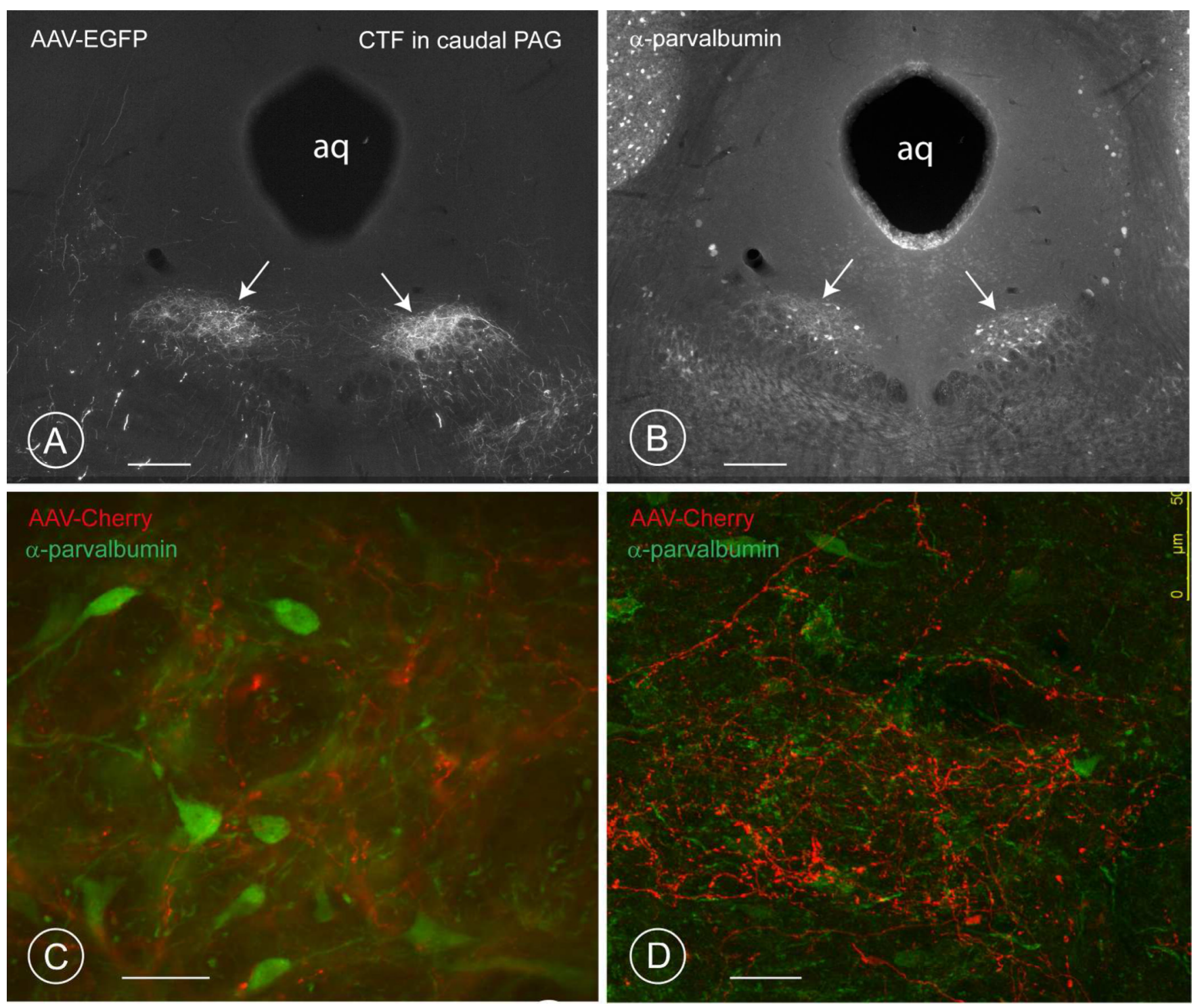

Fig. 8. Distribution of terminal fields in the caudal PAG of mice

A-B: At the fourth and last level of the PAG (approx. level -4.6 in (Paxinos and Franklin, 2001)), the PV1-CTF flares out and becomes oval (white arrows in A), expands in the reticular formation, and impinges upon a nucleus that is composed of parvalbuminimmunoreactive neurons (B). We have named this uncharted nucleus the PV2 nucleus (injection 503-12, bilaterally in the PV1 with the AAV2/9.CAG.FLEX.EGFP.WPRE.bGH constructs). Scale bar $0.3 \mathrm{~mm}$. C-D: At higher magnification, the density of terminals in the ventrolateral cylinder of terminals can be better appreciated ( $N$, injection 237/11). The intimate relationship between the endings from the PV1-nucleus (red) and the parvalbuminpositive neurons in the PV2-nucleus (green) suggest possible synaptic contacts. C: image taken with the fluorescence microscope (injection 237/11). D: stack of laser scanning confocal images to visualize a similar level to $C$ in injection $218 / 11$. Scale bar in C and D: $20 \mu \mathrm{m}$. A magenta-green version of this image is included as supplementary figure number 4. 

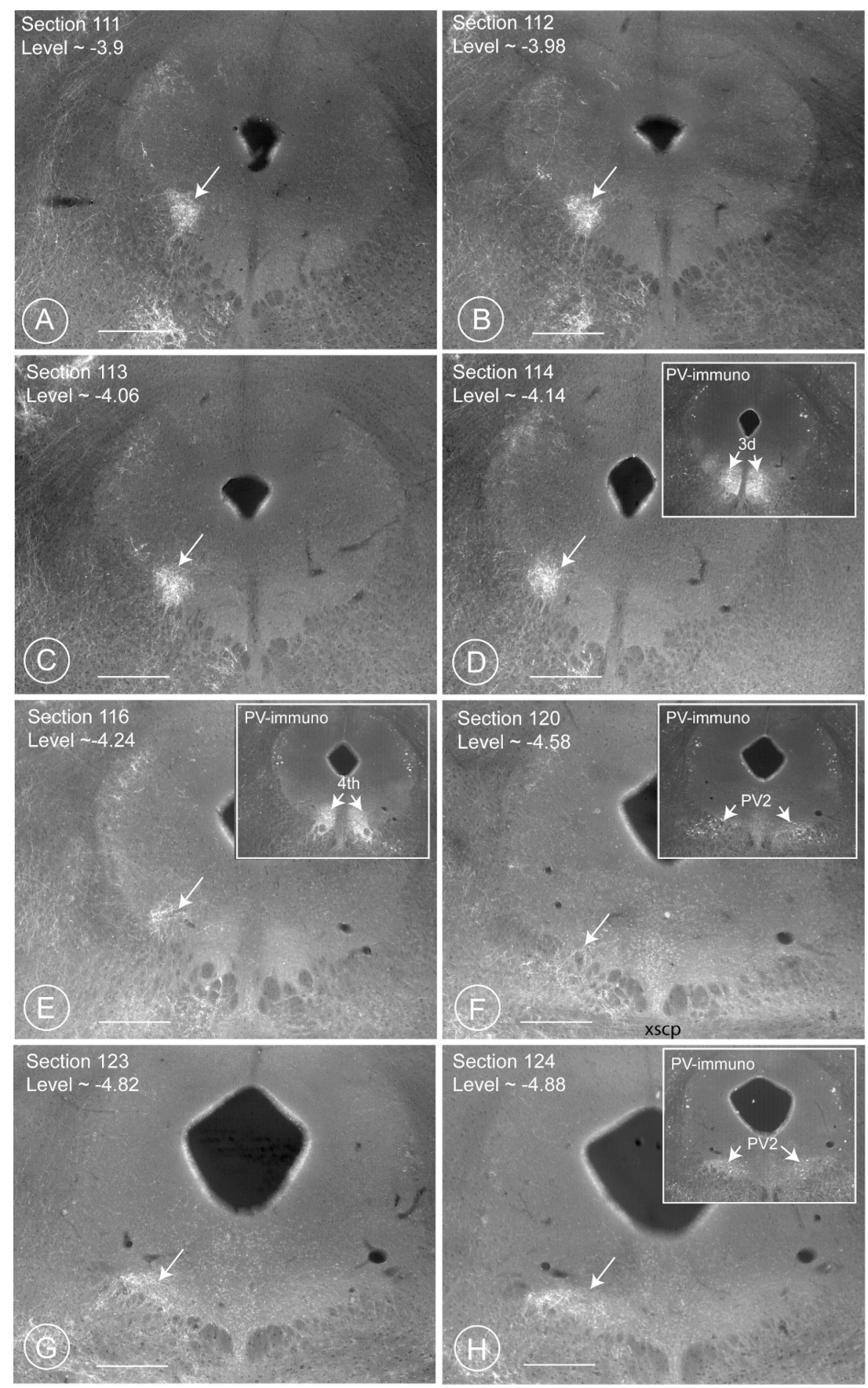

Fig. 9. The cylinder of terminal fields (PV1-CTF) ventrolateral to the aqueduct

Images of eight consecutive sections cut through the periaqueductal gray region of brain 64/12. The rich terminal field ventrolateral to the aqueduct is highlighted by a white arrow. The roundish terminal field is clearly visible from levels 3.9 to 4.14 (Figs. A, B, C and D). It vanishes at level 4.24 (Fig. E) between section 117 and 119 (Bregma 4.30-4.50) and reappears as an oval shaped terminal field in section 120 and can be followed for some more sections (Figs. E, F, G), until section 125-126 (not shown). The insets in D, E, F, and H show the corresponding immunostaining with parvalbumin-antibodies. Notice the presence of the oculomotor nucleus at level 4.14 (Fig. D). The terminal field is absent in a stretch of approximately $250 \mu \mathrm{m}$, encompassing the region where the nucleus of the $4^{\text {th }}$ cranial nerve 
(N. trochlearis) is located. Compare these figures with the three dimensional reconstruction in the drawing of Fig. 11 (mouse) and Fig. 2C (rat). Scale bar $0.4 \mathrm{~mm}$. 

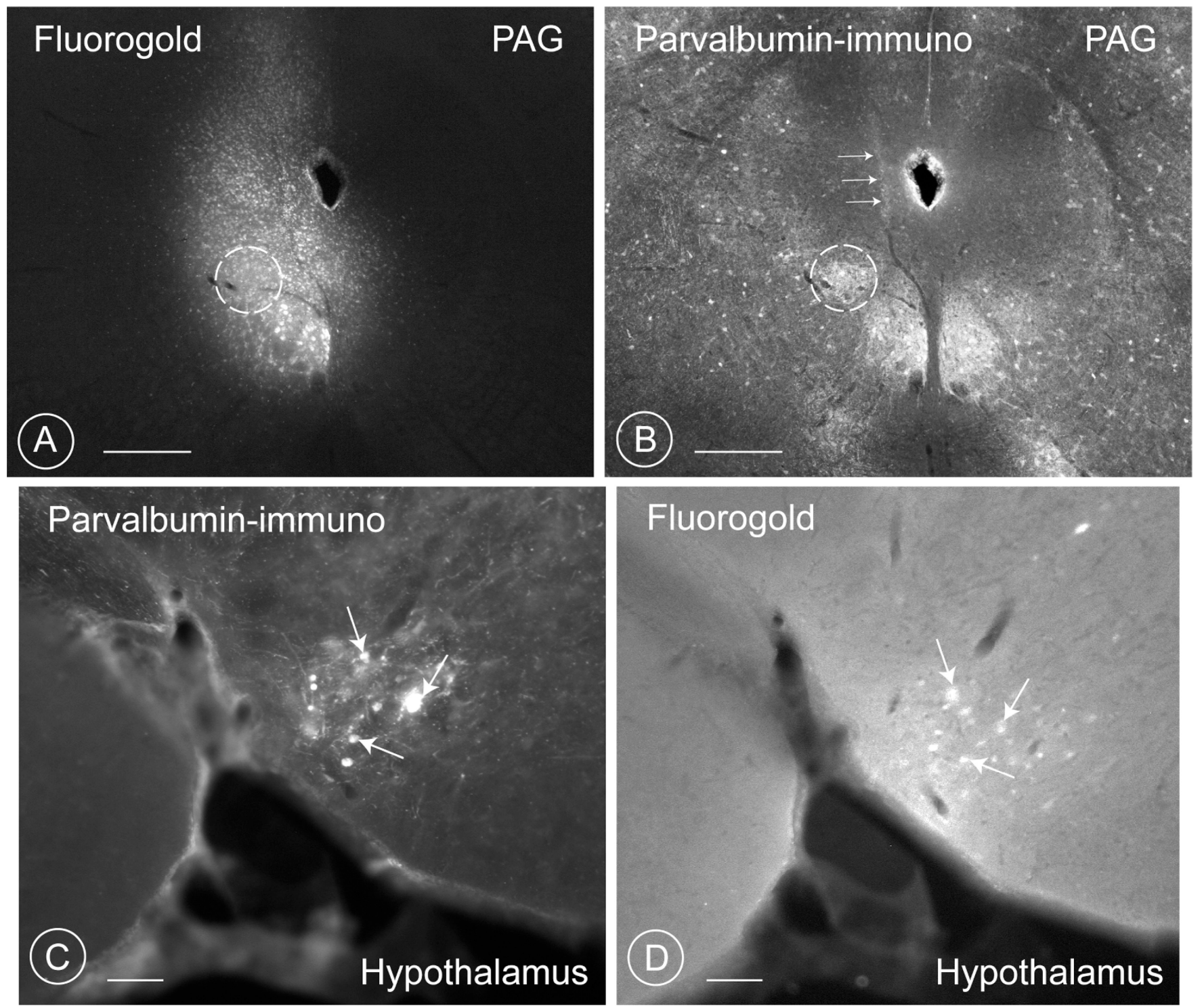

Fig. 10. Retrogradely labelling of neurons in the mouse PV1-nucleus after fluorogold injection at the level of the ventrolateral PAG

Fluorogold applied in the ventrolateral region of the PAG (A), including the region (circle) characterized by a high concentration of parvalbumin-positive terminals (circle in B). Notice the needle track in B (white horizontal arrows). Scale bar $0.6 \mathrm{~mm}$.

At the level of the PV1 nucleus of the hypothalamus (C), many neurons are filled with retrograde tracers (D) and three parvalbumin-positive neurons are indicated by arrows. Scale bar $0.2 \mathrm{~mm}$. 


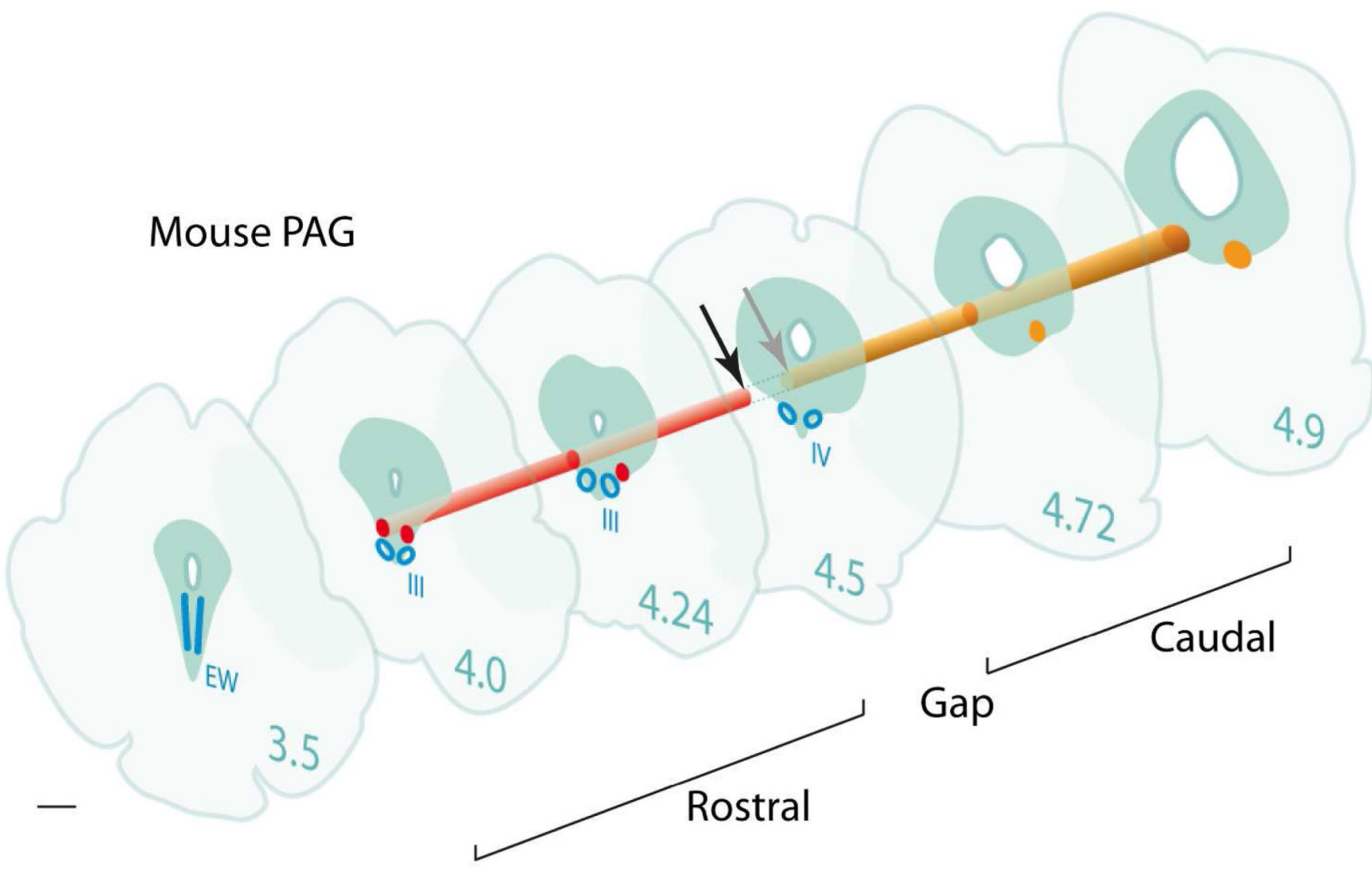

Fig. 11. Three dimensional reconstruction of the column of terminal fields (PV1-CTF) originating in the PV1 (mouse PAG)

Three-dimensional reconstruction of the PAG in mice at six different rostro-caudal levels, revealing the approximate localization of the major terminal field located ventrolateral to the aqueduct. The numbers indicate the different A-P levels in the atlas of (Paxinos and Franklin, 2001). The colum of endings consists of two portions, a rostral (red) and a caudal (orange) field, between levels $-4.0 \mathrm{~mm}$ and $-4.9 \mathrm{~mm}$, separated by short gap (arrows) between $-4.5 \mathrm{~mm}$ and $-4.6 \mathrm{~mm}$. In the caudal half, the endings impinge on a cluster of parvalbumin-positive neurons, that we name the PV2 group. Drawings modified from (VanderHorst and Ulfhake, 2006). Scale bar $0.6 \mathrm{~mm}$. 


\title{
Table 1
}

\section{Abbreviations}

\begin{abstract}
3: Oculomotor nucleus
4: Trochlear Nucleus
\end{abstract}

AAV: Adeno-associated virus

AcbC: Accubens nucleus, core

AHiAL: Amygdalohippocampal area, anterolateral part

AHiPM: Amygdalohippocampal area, posteromedial part

AID: Agranular insular cortex, dorsal part

AIV: Agranular insular cortex, ventral part

AVPO: Anteroventral Preoptic Nucleus

B: Basal nucleus of Meynert

Barr: Barrington's nucleus

BDA: Biotinylated dextran

BST: Bed nucleus of the stria terminalis

BSTL: Bed nucleus of the stria terminalis, lateral division

BSTMA: Bed nucleus of the stria terminalis, medial division, anterior part

BSTMPI: Bed nucleus of the stria terminalis, medial division, posterointermediate part

BSTMPL: Bed nucleus of the stria terminalis, medial division, posterolateral part

BSTV: Bed nucleus of the stria terminalis, ventral division

Ce: Central amygdaloid nucleus

CG: Central (periaqueductal) gray

CG: (med) Central gray, medial part

CGA: Central gray, alpha part

CLi: Caudal linear nucleus of the raphe

DMTg: Dorsomedial tegmental area

DP: Dorsal peduncular cortex

DR: Dorsal raphe nucleus

DRV: Dorsal raphe nucleus, ventral part

DTT: Dorsal taenia tecta

EW: Edinger-Westphal nucleus

F: fornix

FG: Fluorogold

HDB: Nucleus of the horizontal limb of the diagonal band

HRP: Horseradish peroxidase

IG: Indusium griseum

IL: Infralimbic cortex

IPC: Interpeduncular nucleus, caudal subnucleus

IPR: Interpeduncular nucleus, rostral subnucleus

KF: Kölliker-Fuse nucleus

LC: Locus coeruleus

LDTg: Laterodorsal tegmental nucleus 
LH: Lateral hypothalamic area

LHb: lateral habenular nucleus

LHbM: Lateral habenular nucleus, medial part

LM: Lateral mammillary nucleus

LPAG: Lateral periaqueductal gray

LPB: Lateral parabrachial nucleus

LPBC: Lateral parabrachial nucleus, superior part

LPBE: Lateral parabrachial nucleus, external part

LPBS: Lateral parabrachial nucleus, central part

LPO: Lateral preoptic area

LS: Lateral septal nucleus

LSD and LSV Lateral septal nucleus, dorsal- and ventral part

LSI Lateral septal nucleus, intermediate part

me5: mesencephalic fifth nerve

mfb: medial forebrain bundle

mlf: medial longitudinal fascicle

mn5: Motor nucleus of trigeminal nerve

MdD: Medullary reticular nucleus, dorsal part

MGP: Medial globus pallidus

MiTg: Microcellular tegmental nucleus

MnPO: Median preoptic nucleus

MO: Medial orbital cortex

MPA: Medial preoptic area

MPB: Medial parabrachial nucleus

$\mathrm{mt}$ : mammillio-thalamic tract

NRTh: reticular thalamic nucleus

O: Nucleus O

PAG: Periaqueductal gray

PB: Parabrachial nucleus

PBP: Parabrachial pigmented nucleus

PC: Paracentral thalamic nucleus

PCRt: Parvicellular reticular nucleus

PDTg: Posterodorsal tegmental nucleus

PFA: Paraformaldehyde

PH: Posterior hypothalamic area

PHAI: Phaseolus leucoagglutinin

PN: Paranigral nucleus

$\mathrm{PnV}$ : pontine reticular nucleus, ventral part

PPTg: Pedunculopontine tegmental nucleus

PrL: Prelimbic cortex

PV: Paraventricular thalamic nucleus

PV1: Parvalbumin-positive nucleus of the lateral hypothalamus

PV1-CTF: cylinder of PV1-terminal fields ventrolateral to the aqueduct 
PV2: Parvalbumin-positive nucleus ventral of the metencephalic aqueduct

PVA: Paraventricular thalamic nucleus, anterior part

PVP: Paraventricular thalamic nucleus, posterior part

Rf: Fasciculus retroflexus

RMC : Red nucleus, magnocellular

RpN: Raphe pontis nucleus

RRF: Retrorubral field

Rth: Reticular thalamic nucleus

RtTgP: Reticulotegmental nucleus of the pons, pericentral part

RVRG: Rostral ventral respiratory group

SC: superior colliculus

SFO: Subfornical organ

SHi: Septohippocampal nucleus

SI: Substantia innominata

SNR: Substantia nigra, reticular part

SOL: Nucleus of solitary tract

SolM: Nucleus of the solitary tract, medial part

SolVL: Nucleus of solitary tract, ventro-lateral part

SPTg: Subpeduncular tegmental nucleus

STh: Subthalamic nucleus

Su3: Supraoculomotor central gray

SubCV: subcoeruleus nucleus, ventral part

SuM: Supramammillary nucleus

SuML: Supramammillary nucleus, lateral part

VDB: Nucleus of the vertical limb of the diagonal band

vlPAG: ventrolateral PAG

VTA: Ventral tegmental area

VP: Ventral pallidum

VTT: Ventral taenia tecta

$\mathrm{WG}_{\mathrm{A}}$ : Wheat germ agglutinin

ZI: zona incerta 
Table 2

Antibodies used

\begin{tabular}{|l|l|l|l|}
\hline PV235 & $\begin{array}{l}\text { Purified carp } \\
\text { parvalbumin }\end{array}$ & Swant Inc. & $\begin{array}{l}\text { Mouse monoclonal } \\
\text { Lot 10-11F }\end{array}$ \\
\hline PV28/25 & $\begin{array}{l}\text { Recombinant } \\
\text { rat } \\
\text { parvalbumin }\end{array}$ & Swant Inc. & $\begin{array}{l}\text { Rabbit polyclonal } \\
\text { Lot 5.10 }\end{array}$ \\
\hline CART & $\begin{array}{l}\text { Synthetic } \\
\text { peptide } \\
\text { (amino acids } \\
55-102)\end{array}$ & $\begin{array}{l}\text { Phoenix } \\
\text { Pharmaceuticals }\end{array}$ & $\begin{array}{l}\text { Rabbit polyclonal } \\
\text { (lot 00324) }\end{array}$ \\
\hline
\end{tabular}


Table 3

Projections of neurons located within or close to the rat PV1 nucleus

\begin{tabular}{|c|c|c|c|}
\hline Experiment & Tracer & Injection site & Stained fibres and terminals in: \\
\hline R93 & WGA-HRP & $\begin{array}{l}\text { Lateral } \\
\text { hypothalamus }\end{array}$ & $\begin{array}{l}\text { DP, IL (lower layers V-VI), LSI, LSD and LSV } \\
\text { VDB, HDB, MPA, BSTV, BSTVI, BSTMA, } \\
\text { AVPO, LPO, BSTL, BSTMPL, BSTMPI, } \\
\text { AHiAL, LHBM (bilateral), AHiPM, SuM, } \\
\text { IPR, PAG (mid), PN,VTA, SNR, IPC, } \\
\text { RRF, PAG (low), Cli, Su3, PPTg, DR, } \\
\text { PAG, LPBS, LPBC, LPBE, MPB, LPB, } \\
\text { LDTg, Rpn, Barr, DMTg, CGA, O, LC, } \\
\text { between LC and PDTg, SolM, SOL. }\end{array}$ \\
\hline R 189 & WGA-HRP & $\begin{array}{l}\text { Lateral } \\
\text { hypothalamus }\end{array}$ & $\begin{array}{l}\text { LSI, HDB, CLi, DP (or IL), LPAG, PPTg, } \\
\text { PB (some), LDTg, Barr (few), LC, PDTg, }\end{array}$ \\
\hline $\begin{array}{l}\text { R } 451 \\
\text { Fig. } 7 \mathrm{c}\end{array}$ & $\begin{array}{l}\text { Phaseolus } \\
\text { vulgaris } \\
\text { agglutinin } \\
\text { (PHA) }\end{array}$ & $\begin{array}{l}\text { Lateral } \\
\text { hypothalamus }\end{array}$ & $\begin{array}{l}\text { AID, AIV, DP, DTT, SHi, IL, AcbC, IG, } \\
\text { LSD, HDB, VP, BST, Parav. Nu., PV, } \\
\text { PVA, PVP, B, SI, Ce, LHb, PH, LPAG } \\
\text { EW, Su3, 3, VTA, RRF, RtTgP, Pptg, } \\
\text { Sptg, LDTg, Barr-region, LPB, MPB } \\
\text { SubCV, PnV, PCRt, SolVL, MdD, Sol }\end{array}$ \\
\hline R 877 & $\begin{array}{l}\text { Phaseolus } \\
\text { vulgaris } \\
\text { agglutinin } \\
\text { (PHA) }\end{array}$ & Tuber cinereum & $\begin{array}{l}\text { Prl, MO, IL (lower layers V-VI), DP, DTT, } \\
\text { Shi, VDB, LHb (terminals), Ce, PAG, LH, } \\
\text { SuML, PBPPP, DLPA, GRLi, VTA, MiTg, } \\
\text { PB, KFCGA, RVRG }\end{array}$ \\
\hline R 878 & $\begin{array}{l}\text { Phaseolus } \\
\text { vulgaris } \\
\text { agglutinin } \\
\text { (PHA) }\end{array}$ & $\begin{array}{l}\text { Supraoptic } \\
\text { nucleus }(+ \\
\text { anteriormost } \\
\text { part of PV1) }\end{array}$ & $\begin{array}{l}\text { Prl, IL, MO, VTT, IL, DP, AIV, AID, VDB, } \\
\text { LS, MnPO, SFO, LHbM, DRV, PB, LDTg } \\
\text { RVGR }\end{array}$ \\
\hline
\end{tabular}

The regions indicated in red, bold typeface are those that have been shown in the present study to be targeted by the PV1-nucleus. The regions written in italics are those which have been demonstrated to have no connections with the PV1-nucleus. The terminal fields observed in experiment R93, R189 and R451, are depicted in Fig. 2B. 


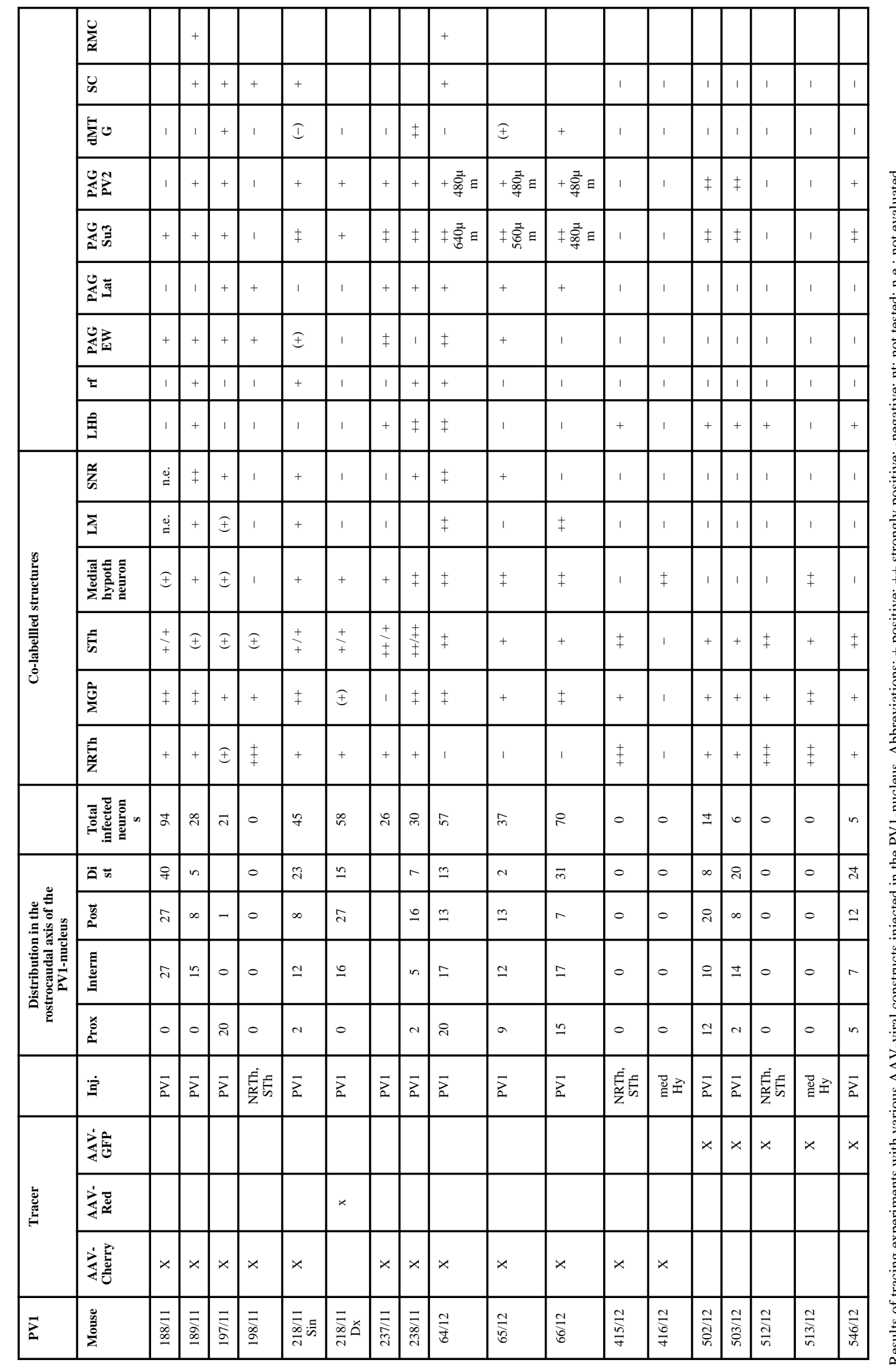

